\title{
Myocardial perfusion scintigraphy: the evidence
}

\section{A consensus conference organised by the British Cardiac Society, the British Nuclear Cardiology Society and the British Nuclear Medicine Society, endorsed by the Royal College of Physicians of London and the Royal College of Radiologists} \author{
A. Al-Mohammad8, E. M. Prvulovich ${ }^{9}$, L. J. Shaw ${ }^{10}$, A. C. Tweddel ${ }^{11}$ \\ 1 Imperial College London, Royal Brompton Hospital, London, UK \\ 2 Royal Brompton Hospital, London, UK \\ ${ }^{3}$ Georgetown University Medical Center, Washington DC, USA \\ ${ }^{4}$ Institute of Nuclear Medicine, UCL, The Middlesex Hospital, London, UK \\ ${ }^{5}$ Dudley Group of Hospitals, Wordsley Hospital, Stourbridge, West Midlands, UK \\ ${ }^{6}$ Antrim Area Hospital, Co Antrim, N. Ireland, UK \\ ${ }^{7}$ Harefield Hospital, Harefield, Middlesex, UK \\ 8 Northern General Hospital, Sheffield, UK \\ 9 Institute of Nuclear Medicine, UCL, The Middlesex Hospital, London, UK \\ 10 Suite 225, Atlanta Cardiovascular Research Institute, Atlanta, Georgia, USA \\ 11 Castle Hill Hospital, Cottingham, E Yorkshire, UK
}

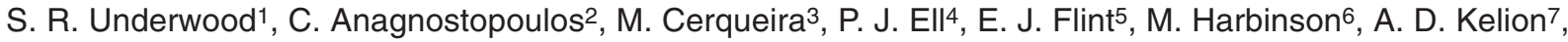

Published online: 25 November 2003

(C) Springer-Verlag 2003

\begin{abstract}
This review summarises the evidence for the role of myocardial perfusion scintigraphy (MPS) in patients with known or suspected coronary artery disease. It is the product of a consensus conference organised by the British Cardiac Society, the British Nuclear Cardiology Society and the British Nuclear Medicine Society and is endorsed by the Royal College of Physicians of London and the Royal College of Radiologists. It was used to inform the UK National Institute of Clinical Excellence in their appraisal of MPS in patients with chest pain and myocardial infarction. MPS is a well-established, non-invasive imaging technique with a large body of evidence to support its effectiveness in the diagnosis and management of angina and myocardial infarction. It is more accurate than the exercise ECG in detecting myocardial ischaemia and it is the single most powerful technique for predicting future coronary events. The high diagnostic accuracy of MPS allows reliable risk stratification and guides the selection of patients for further interventions, such as revascularisation. This in turn allows more appropriate utilisation of resources, with the potential for both improved clinical outcomes and greater cost-effectiveness. Evidence from modelling and obser-
\end{abstract}

\footnotetext{
S. R. Underwood ( $\bullet$ )

Imperial College London, Royal Brompton Hospital,

Sydney St, London, SW3 6NP, UK

e-mail: r.underwood@imperial.ac.uk
}

vational studies supports the enhanced cost-effectiveness associated with MPS use. In patients presenting with stable or acute chest pain, strategies of investigation involving MPS are more cost-effective than those not using the technique. MPS also has particular advantages over alternative techniques in the management of a number of patient subgroups, including women, the elderly and those with diabetes, and its use will have a favourable impact on cost-effectiveness in these groups. MPS is already an integral part of many clinical guidelines for the investigation and management of angina and myocardial infarction. However, the technique is underutilised in the UK, as judged by the inappropriately long waiting times and by comparison with the numbers of revascularisations and coronary angiograms performed. Furthermore, MPS activity levels in this country fall far short of those in comparable European countries, with about half as many scans being undertaken per year. Currently, the number of MPS studies performed annually in the UK is $1,200 /$ million population/year. We estimate the real need to be $4,000 /$ million/year. The current average waiting time is 20 weeks and we recommend that clinically appropriate upper limits of waiting time are 6 weeks for routine studies and 1 week for urgent studies.

Abbreviations. Acc Diagnostic accuracy - ACS Acute coronary syndromes - BCS British Cardiac Society . $B N C S$ British Nuclear Cardiology Society - BNMS Brit- 
ish Nuclear Medicine Society - $C A B G$ Coronary artery bypass grafting $\cdot C H D$ Coronary heart disease $\cdot C T$ Computed X-ray tomography - $\angle B B B$ Left bundle branch block - MI Myocardial infarction - MIBI Technetium99m 2-methoxy-isobutyl-isonitrile · MPS Myocardial perfusion scintigraphy - NSF National Service Framework for Cardiovascular Disease - NSTEMI Non-ST segment elevation myocardial infarction $\cdot$ PCI Percutaneous coronary intervention . $Q$ Quantitative analysis . $Q A L Y$ Quality-adjusted life-year $\cdot R C P$ Royal College of Physicians of London $R C R$ Royal College of Radiologists - Sens Sensitivity - Spec Specificity - SPET Singlephoton emission tomography - STEMI ST segment elevation myocardial infarction - Tetro or tetrofosmin Technetium-99m 1,2-bis[bis(2-ethoxyethyl) phosphino] ethane . $201 T$ or thallium Thallium-201 thallous chloride . $U A$ Unstable angina $\cdot V$ Visual analysis

Eur J Nucl Med Mol Imaging (2004) 31:261-291 DOI 10.1007/s00259-003-1344-5

\section{Introduction}

\section{Background}

Coronary heart disease (CHD) is a major cause of mortality and morbidity in Europe and its management consumes a large proportion of national healthcare budgets. New imaging technologies have added to the immediate costs of investigation but they also have the potential to reduce overall costs, by virtue of their greater diagnostic and prognostic accuracy. This allows a more informed selection of therapy, which in turn can lead to a better clinical outcome.

Myocardial perfusion scintigraphy (MPS) is an established imaging technique that is already an integral part of the management of CHD and is included in a number of professional guidelines. Its most important applications are in the diagnosis of CHD, prognostication, selection for revascularisation and assessment of acute coronary syndromes, and it is of special value in some patient subgroups.

In this consensus document we review the evidence supporting the clinical effectiveness and cost-effectiveness of MPS and we assess its potential to improve patient care in the UK. The current utilisation of MPS is reviewed and targets for service improvements are proposed.

\section{Description of process for consensus meeting}

Representatives of the British Cardiac Society (BCS), the British Nuclear Cardiology Society (BNCS) and the British Nuclear Medicine Society (BNMS) met at a con- sensus conference in January 2003 to review the evidence for the clinical and cost-effectiveness of MPS and to draft a document for submission to the National Institute for Clinical Excellence (NICE). The document was a submission for the NICE appraisal of MPS in the diagnosis and management of angina and myocardial infarction. The final document was endorsed by the three societies and also by the Royal College of Physicians of London (RCP) and the Royal College of Radiologists (RCR).

\section{What is MPS?}

MPS was developed in the 1970s and has been used increasingly in clinical cardiology since the 1980s. Technical developments that have fuelled this recent increase are single-photon emission tomographic imaging (SPET), pharmacological stress and ECG-gated imaging.

The technique involves intravenous injection of small amounts of a radioactive tracer, usually during some form of cardiovascular stress. The three commercially available tracers are thallium-201 thallous chloride (thallium), technetium-99m 2-methoxy-isobutyl-isonitrile (MIBI) and technetium-99m 1,2-bis[bis(2-ethoxyethyl) phosphino] ethane (tetrofosmin). These are avidly extracted by cardiac myocytes and hence their initial myocardial distribution reflects a combination of the distribution of myocytes and perfusion. Comparison of images following stress and rest injections of tracer (or following redistribution for thallium) allows myocardial viability and perfusion to be assessed independently.

Pharmacological stress, using a vasodilator such as adenosine or a beta sympathetic agonist such as dobutamine, allows patients who cannot achieve maximal cardiovascular stress on a treadmill to be studied, and this is a particularly valuable aspect of the technique that is relevant to between one-third and one-half of patients.

SPET is the preferred imaging technique, whereby the camera rotates around the patient over 10-20 min and the resulting set of planar projection images are reconstructed into a three-dimensional stack of tomographic slices through the myocardium. The tomograms are displayed using a colour scale to provide a semi-quantitative assessment of regional tracer uptake, and comparison with databases of normal appearances allows objective assessment of the presence, depth and extent of abnormalities. The stress and rest images are normally separated by $3-4 \mathrm{~h}$ but the total patient contact time for stress, injection and image acquisition is approximately 45 min.

Homogeneous myocardial uptake of tracer indicates normal myocardium and perfusion and hence the absence of clinically significant infarction or coronary stenosis. A defect in the stress images that normalises in the rest images (a reversible defect) indicates an inducible perfusion abnormality and normally corresponds to a 
significant coronary stenosis. A defect in both stress and rest images (a fixed defect) indicates an area with loss of viable myocardium such as after myocardial infarction. The site, extent and depth of these abnormalities are readily assessed and hence the technique is valuable for the diagnosis of CHD, for assessing its severity, which in turn is related to prognosis, and for assessing global and regional myocardial function from ECG-gated moving images.

\section{Safety}

MPS is non-invasive and safe, particularly in comparison with invasive investigation, which it can sometimes replace. The complication rate of dynamic exercise is well established from treadmill exercise electrocardiography as at most $0.01 \%$ deaths and $0.02 \%$ morbidity [1] and similar rates have been observed with pharmacological stress $[2,3,4]$. These low rates are at least two orders of magnitude less than the risk of underlying CHD and so, except in patients with unstable CHD or other contraindications to stress, the risk is not normally considered significant.

The radiation exposure to the patient is $10 \mathrm{mSv}$ for a $1,000 \mathrm{MBq}$ tetrofosmin study, $12 \mathrm{mSv}$ for a $1,000 \mathrm{MBq}$ MIBI study and $18 \mathrm{mSv}$ for an $80 \mathrm{MBq}$ thallium study [5]. A $10 \mathrm{mSv}$ exposure is equivalent to 5 years of natural background radiation; it is similar to the exposure from computed X-ray tomography (CT) and coronary angiography [6] and it produces a 1 in 1,800 risk of cancer 10-20 years after the exposure [7]. Although this is higher than the risk of the stress test, it is small alongside the lifetime risk of cancer in the general population ( 1 in 3 ), and it is of even lesser importance in the elderly and those with known CHD, the population that is most commonly referred for MPS.

Coronary angiography is complicated by death in $0.1 \%$ of cases and by non-fatal events such as myocardial infarction, stroke and emergency bypass grafting in $2 \%$ [8]. Lesser complications such as bleeding, dissection and thrombosis of the vascular access site occur in $0.5 \%[8]$.

\section{Diagnosis}

\section{Coronary angiography and myocardial perfusion}

MPS is the only widely available method of assessing myocardial perfusion directly. It therefore has a clear role in the diagnosis of CHD in patients presenting with chest pain. An inducible perfusion abnormality indicates impaired perfusion reserve, which in turn usually corresponds to epicardial coronary obstruction. The site, depth and extent of the abnormality provide diagnostic and management information that cannot be determined reliably from other tests such as the ECG. Conversely, normal stress MPS indicates the absence of coronary obstruction and hence of clinically significant disease. It is important to note that normal perfusion does not exclude non-obstructive coronary disease, but such disease is unlikely to be related to symptoms and is not prognostically important (see section "Prognosis").

Coronary angiography is the standard technique for assessing epicardial coronary anatomy and MPS is the standard technique for assessing myocardial perfusion. Although the anatomical extent of disease is best demonstrated by coronary angiography, MPS provides a complementary assessment of its physiological significance and hence information on important features such as endothelial function, small vessel function and collateralisation, in addition to the haemodynamic significance of epicardial stenoses. Discrepancies between coronary anatomy and myocardial perfusion do not necessarily indicate a failure in the assessment of either; instead they indicate the complexity of the relationship. Complete accuracy of MPS to predict the findings at coronary angiography is neither expected nor necessary for clinical management, and when MPS is used for the diagnosis of CHD it is not being used purely to predict the presence of epicardial coronary disease. Nevertheless, the coronary angiogram is an accepted standard for imaging the coronary arteries and functional tests such as MPS are commonly compared with angiography.

\section{Diagnostic accuracy of MPS}

Many studies have assessed the diagnostic accuracy of MPS for the detection of coronary heart disease, but they are of variable size and quality. Tables $1,2,3$ and 4 summarise the findings according to the four main forms of stress and also grade the quality of the studies according to accepted principles $[9,10]$. The highest quality score is 3 , when the study involves a clearly defined population, when it avoids verification bias and when MPS is interpreted independently of angiography. A quality score of 2 fulfils two of these criteria and a score of 1 only one criterion. An additional criterion of quality is the exclusion of patients with previous infarction since the most relevant population is the diagnostic study, where MPS may be less sensitive than in patients with previous infarction and abnormal resting images.

\section{Sensitivity and specificity}

Because of the variation in study size, quality and design, we have avoided giving weighted averages of sensitivity and specificity in the above tables. Specificity in particular varies between studies depending upon patient population, nature of reporting and referral bias (see section "Factors affecting observed diagnostic perfor- 
Table 1. Diagnostic accuracy of exercise MPS for the detection of $\geq 50 \%$ coronary stenosis defined angiographically

\begin{tabular}{|c|c|c|c|c|c|c|c|c|}
\hline Author, year [ref.] & No. & Tracer & Analysis & MI excluded & Quality & Sens $(\%)$ & $\operatorname{Spec}(\%)$ & $\operatorname{Acc}(\%)$ \\
\hline Tamaki, 1984 [11] & 104 & ${ }^{201} \mathrm{Tl}$ & Q & Both $^{\mathrm{a}}$ & 2 & 98 & 91 & 96 \\
\hline DePasquale, 1988 [12] & 210 & ${ }^{201} \mathrm{Tl}$ & $\mathrm{Q}$ & Both $^{\mathrm{a}}$ & 2 & 95 & 74 & 92 \\
\hline Fintel, 1989 [13] & 135 & ${ }^{201} \mathrm{Tl}$ & V & No & 2 & 83 & - & - \\
\hline Iskandrian, 1989 [14] & 193 & ${ }^{201} \mathrm{Tl}$ & $\mathrm{V}$ & Yes & 2 & 86 & 62 & 79 \\
\hline Maddahi, 1989 [15] & 110 & ${ }^{201} \mathrm{Tl}$ & Q & Both $^{\mathrm{a}}$ & 3 & 95 & 56 & 88 \\
\hline Mahmarian, 1990 [16] & 296 & ${ }^{201} \mathrm{Tl}$ & Q & Both $^{\mathrm{a}}$ & 3 & 87 & 87 & 87 \\
\hline Van Train, 1990 [17] & 242 & ${ }^{201} \mathrm{Tl}$ & Q & Both $^{\mathrm{a}}$ & 2 & 94 & 43 & 85 \\
\hline Coyne, 1991 [18] & 100 & ${ }^{201} \mathrm{Tl}$ & $\mathrm{V}$ & No & 2 & 81 & 74 & 77 \\
\hline Quinones, 1992 [19] & 112 & ${ }^{201} \mathrm{Tl}$ & $\mathrm{V}$ & Yes & 1 & 77 & 81 & 78 \\
\hline Chae, 1993 [20] & 243 & ${ }^{201} \mathrm{Tl}$ & $\mathrm{V}$ & No & 3 & 71 & 63 & 69 \\
\hline Grover-McKay, 1994 [21] & 18 & ${ }^{201} \mathrm{Tl}$ & $\mathrm{V}$ & No & 1 & 91 & 86 & 89 \\
\hline Tamaki, 1994 [22] & 25 & ${ }^{201} \mathrm{Tl}$ & $\mathrm{V}$ & No & 1 & 95 & 33 & 88 \\
\hline Ho, 1997 [23] & 51 & ${ }^{201} \mathrm{Tl}$ & $\mathrm{V}$ & Both $^{\mathrm{a}}$ & 3 & 76 & 77 & 76 \\
\hline Kiat, 1990 [24] & 53 & MIBI & Q & Both $^{\mathrm{a}}$ & 2 & 94 & 80 & 92 \\
\hline Pozzoli, 1991 [25] & 75 & MIBI & V & No & 1 & 84 & 88 & 85 \\
\hline Solot, 1993 [26] & 78 & MIBI & $\mathrm{V}$ & No & 2 & 96 & 74 & 90 \\
\hline Marwick, 1994 [27] & 86 & MIBI & $\mathrm{V}$ & Yes & 2 & 73 & 70 & 72 \\
\hline Van Train, 1994 [28] & 124 & MIBI & Q & Both $^{\mathrm{a}}$ & 2 & 89 & 36 & 81 \\
\hline Tamaki, 1994 [22] & 26 & Tetro & $\mathrm{V}$ & No & 1 & 96 & 67 & 92 \\
\hline Нeo, 1994 [29] & 23 & Tetro & $\mathrm{V}$ & No & 2 & 87 & - & - \\
\hline Benoit, 1996 [30] & 30 & Tetro & $\mathrm{V}$ & Yes & 2 & 81 & 89 & 83 \\
\hline Shanoudy, 1998 [31] & 26 & Tetro & $\mathrm{V}$ & No & 2 & 96 & - & - \\
\hline
\end{tabular}

${ }^{201} \mathrm{Tl}$, Thallium-201 thallous chloride; MIBI, technetium-99m 2-methoxy-isobutyl-isonitrile; Tetro, technetium-99m 1,2-bis[bis(2-ethoxyethyl) phosphino] ethane; V, visual analysis; Q, quantitative anala Accuracy reported in full group and in subset without infarction; figures in table relate to whole patient group ysis; MI, myocardial infarction; Sens, sensitivity; Spec, specificity; Acc, accuracy

Table 2. Diagnostic accuracy of dipyridamole MPS for the detection of $\geq 50 \%$ (or $\geq 70 \%$ a) coronary stenosis defined angiographically

\begin{tabular}{|c|c|c|c|c|c|c|c|c|}
\hline Author, year [ref.] & No. & Tracer & Analysis & MI excluded & Quality & Sens $(\%)$ & Spec $(\%)$ & $\operatorname{Acc}(\%)$ \\
\hline Francisco, $1982[32]^{\mathrm{a}}$ & 75 & ${ }^{201} \mathrm{Tl}$ & $\mathrm{Q}$ & No & 2 & 90 & 96 & 92 \\
\hline Huikuri, $1988[33]^{\mathrm{a}}$ & 93 & ${ }^{201} \mathrm{Tl}$ & $\mathrm{V}$ & No & 2 & 96 & 75 & 94 \\
\hline Go, $1990[34]$ & 202 & ${ }^{201} \mathrm{Tl}$ & $\mathrm{V}$ & Both ${ }^{b}$ & 3 & 76 & 80 & 77 \\
\hline Mendelson, 1992 [35] ${ }^{\mathrm{a}}$ & 79 & $201 \mathrm{Tl}$ & $\mathrm{V}$ & Both ${ }^{b}$ & 2 & 90 & - & - \\
\hline Cramer, 1994 [36] & 38 & ${ }^{201} \mathrm{Tl}$ & $\mathrm{V}$ & No & 3 & 90 & 71 & 87 \\
\hline Grover-McKay, 1994 [21] & 18 & ${ }^{201} \mathrm{Tl}$ & $\mathrm{V}$ & Unknown & 1 & 91 & 100 & 94 \\
\hline Ho, 1995 [37] & 54 & ${ }^{201} \mathrm{Tl}$ & $\mathrm{V}$ & No & 3 & 98 & 73 & 93 \\
\hline Watanabe, 1997 [38] & 53 & ${ }^{201} \mathrm{Tl}$ & $\mathrm{V}$ & Yes & 2 & 80 & 72 & 77 \\
\hline Tartagni, 1991 [39] & 30 & $\begin{array}{l}201 \mathrm{Tl} ; \\
\text { MIBI }\end{array}$ & $\mathrm{V}$ & No & 2 & 100 & 75 & 97 \\
\hline Miller, 1997 [40] & 244 & MIBI & $\mathrm{V}$ & Both $^{b}$ & 2 & 91 & 28 & 81 \\
\hline Schillaci, 1997 [41] & 40 & MIBI & $\mathrm{V}$ & Yes & 1 & 95 & 72 & 85 \\
\hline Soman, 1997 [42] & 27 & MIBI & $\mathrm{V}$ & No & 3 & 90 & 66 & 89 \\
\hline Ogilby, 1998 [43] & 26 & MIBI & $\mathrm{V}$ & No & 2 & 90 & 100 & 92 \\
\hline Santoro, 1998 [44] & 60 & MIBI & $\mathrm{V}$ & Yes & 3 & 97 & 89 & 93 \\
\hline $\mathrm{He}, 1997$ [45] & 64 & Tetro & $\mathrm{V}$ & No & 2 & 85 & 54 & 80 \\
\hline
\end{tabular}

Abbreviations as defined in Table 1 and list of abbreviations a $\geq 70 \%$ coronary stenosis b Accuracy reported in full group and in subset without infarction; figures in table relate to whole patient group mance"), and averages do not give a clear indication of the performance of the technique.

In the largest single study of 2,560 patients randomised to each of the three tracers and using mainly adeno- sine stress (the ROBUST study, UK based), overall sensitivity in the subset of patients undergoing angiography was $91 \%$ and specificity $87 \%$, with no significant difference between the three tracers [55]. In general terms, 
Table 3. Diagnostic accuracy of adenosine MPS for the detection of $\geq 50 \%$ coronary stenosis defined angiographically

\begin{tabular}{|c|c|c|c|c|c|c|c|c|}
\hline Author, year [ref.] & No. & Tracer & Analysis & MI excluded & Quality & Sens $(\%)$ & Spec $(\%)$ & $\operatorname{Acc}(\%)$ \\
\hline Nguyen, 1990 [46] & 60 & ${ }^{201} \mathrm{Tl}$ & V & No & 2 & 92 & 100 & 93 \\
\hline Verani, 1990 [47] & 45 & ${ }^{201} \mathrm{Tl}$ & Q & No & 2 & 83 & 94 & 87 \\
\hline Coyne, 1991 [18] & 100 & ${ }^{201} \mathrm{Tl}$ & V & Both ${ }^{b}$ & 2 & 83 & 76 & 79 \\
\hline Nishimura, 1991 [48] & 101 & ${ }^{201} \mathrm{Tl}$ & V & Both ${ }^{b}$ & 3 & 84 & 84 & 84 \\
\hline Allman, 1992 [49] & 76 & ${ }^{201} \mathrm{Tl}$ & Q & Yes & 3 & 85 & 38 & 80 \\
\hline Pennell, 1995 [50] & 226 & ${ }^{201} \mathrm{Tl}$ & V & No & 3 & 96 & 78 & 92 \\
\hline Mohiuddin, 1996 [51] & 202 & ${ }^{201} \mathrm{Tl}$ & Q & No & 3 & 90 & 86 & 89 \\
\hline Amanullah, 1993 [52] & 40 & MIBI & V & No & 2 & 94 & 100 & 95 \\
\hline Marwick, 1993 [53] & 97 & MIBI & $\mathrm{V}$ & Yes & 2 & 86 & 71 & 80 \\
\hline Jamil, 1999 [54] & 32 & MIBI & V & No & 2 & 75 & - & - \\
\hline Kapur, $2002[55]^{\mathrm{a}}$ & 2,560 & $\begin{array}{l}201 \mathrm{Tl}, \\
\text { MIBI, } \\
\text { Tetro }\end{array}$ & $\mathrm{V}$ & Yes & 2 & 91 & 87 & 91 \\
\hline
\end{tabular}

Abbreviations as defined in Table 1 and list of abbreviations a $89 \%$ of studies with adenosine and 137 patients undergoing angiography b Accuracy reported in full group and in subset without infarction; figures in table relate to whole patient group

Table 4. Diagnostic accuracy of dobutamine MPS for the detection of $\geq 50 \%$ (or $\geq 70 \%$ a) coronary stenosis defined angiographically

\begin{tabular}{|c|c|c|c|c|c|c|c|c|}
\hline Author, year [ref.] & No. & Tracer & Analysis & MI excluded & Quality & Sens $(\%)$ & Spec $(\%)$ & $\operatorname{Acc}(\%)$ \\
\hline Pennell, 1991 [56] & 50 & ${ }^{201} \mathrm{Tl}$ & $\mathrm{V}$ & No & 2 & 97 & 80 & 94 \\
\hline Warner, 1993 [57] & 16 & ${ }^{201} \mathrm{Tl}$ & $\mathrm{V}$ & No & 2 & 93 & 100 & 94 \\
\hline Huang, 1997 [59] & 93 & ${ }^{201} \mathrm{Tl}$ & $\mathrm{Q}$ & No & 3 & 90 & 81 & 87 \\
\hline Huang, 1998 [60] & 110 & ${ }^{201} \mathrm{Tl}$ & $\mathrm{V}$ & Yes & 3 & 82 & 82 & 82 \\
\hline Caner, 1997 [61] & 29 & $\begin{array}{l}201 \mathrm{Tl} ; \\
\text { MIBI }\end{array}$ & $\mathrm{V}$ & Uncertain & 3 & 89 & 70 & 83 \\
\hline Gunalp, 1993 [62] & 27 & MIBI & $\mathrm{V}$ & Yes & 2 & 94 & 89 & 93 \\
\hline Forster, 1993 [63] & 21 & MIBI & $\mathrm{V}$ & Yes & 3 & 83 & 89 & 86 \\
\hline Marwick, 1993 [53] & 97 & MIBI & $\mathrm{V}$ & Yes & 2 & 80 & 74 & 77 \\
\hline Marwick, 1993 [64] & 217 & MIBI & Q & Yes & 3 & 76 & 67 & 73 \\
\hline Mairesse, 1994 [65] & 129 & MIBI & $\mathrm{V}$ & Yes & 3 & 76 & 65 & 72 \\
\hline Marwick, 1994 [27] & 82 & MIBI & $\mathrm{V}$ & Yes & 2 & 65 & 68 & 66 \\
\hline Slavich, 1996 [70] & 46 & MIBI & $\mathrm{V}$ & Yes & $?$ & 82 & 83 & 83 \\
\hline San Roman, 1998 [71] & 92 & MIBI & $\mathrm{Q}$ & Yes & 3 & 87 & 70 & 82 \\
\hline Santoro, 1998 [44] $^{\mathrm{a}}$ & 60 & MIBI & $\mathrm{Q}$ & Yes & 3 & 91 & 81 & 87 \\
\hline Elhendy, 1998 [72] & 70 & MIBI & $\mathrm{V}$ & No & $?$ & 64 & 72 & 67 \\
\hline
\end{tabular}

Abbreviations as defined in Table 1 and list of abbreviations $\mathrm{a} \geq 70 \%$ coronary stenosis

however, the sensitivity of exercise MPS for detecting angiographically defined CHD is consistently above $70 \%$, but in the better designed studies it is in the region of $85-90 \%[13,14,15]$. Reported specificity varies from $33 \%$ to $100 \%$ but in the better quality studies it is in the region of $70-75 \%[26,27]$, with values up to $94 \%$ when ECG-gated imaging is used [73].

For pharmacological stress studies using thallium, a number of good quality studies show that sensitivity is in the region of $90 \%$ for both dipyridamole $[21,32,35,36]$ and adenosine $[46,51]$ and that specificity is $75-80 \%$ $[18,33,34,39,50]$ although some studies have reported even higher values $(95-100 \%)$ [21, 32, 46]. Results obtained using MIBI are similar to those obtained using thallium [40, 41, 43, 44, 52, 53, 54]. When dobutamine is used with thallium, the sensitivity is in the region of $90 \%$ while the specificity ranges from $81 \%$ to $100 \%$ [56, $57,58,59,60]$. When dobutamine is used with MIBI, 
Table 5. Normalcy values in patients with a low pre-test likelihood of CHD

\begin{tabular}{lrlll}
\hline Author, year [ref.] & No. & Tracer & Stress & Normalcy (\%) \\
\hline Iskandrian, 1989 [14] & 131 & $201 \mathrm{Tl}$ & Exercise & 94 \\
Maddahi, 1989 [15] & 52 & $201 \mathrm{Tl}$ & Exercise & 86 \\
Van Train, 1990 [17] & 76 & $201 \mathrm{Tl}$ & Exercise & 82 \\
Coyne, 1991 [18] & 45 & $201 \mathrm{Tl}$ & Exercise, adenosine & 80 \\
Kiat, 1992 [82] & 55 & ${ }^{201} \mathrm{Tl}$ & Exercise & 89 \\
Nishimura, 1991 [48] & 39 & ${ }^{201} \mathrm{Tl}$ & Exercise & 92 \\
Nishimura, 1991 [48] & 39 & $201 \mathrm{Tl}$ & Adenosine & 95 \\
Van Train, 1994 [28] & 37 & $201 \mathrm{Tl}$ & Exercise & 81 \\
Kiat, 1990 [24] & 8 & MIBI & Exercise & 88 \\
Heo, 1994 [29] & 61 & MIBI & Exercise & 95 \\
Weighted average & 543 & & & 89 \\
\hline
\end{tabular}

most studies have shown that the sensitivity is above $80 \%[53,61,62,63,66,67,69,70,71]$ but the specificity ranges from $64 \%$ to $90 \%[68,69]$.

Fewer diagnostic studies have been performed using tetrofosmin because of its more recent introduction commercially. For exercise studies using tetrofosmin, sensitivity and specificity range from $81 \%$ to $96 \%$ [22, 30, $31]$ and from $67 \%$ to $91 \%[22,30]$ respectively.

Factors affecting observed diagnostic performance

When the reference standard for diagnosis, in this case coronary angiography, is not used in all patients and referral to angiography is more likely when MPS is abnormal, then the findings are affected by referral bias and specificity appears falsely low $[74,75,76,77,78,79$, $80,81]$. Indeed, if only patients with abnormal MPS undergo angiography then the observed sensitivity will be $100 \%$ and the specificity $0 \%$. Normalcy is therefore a better parameter for defining the performance of a test in patients without disease. It is the percentage of studies that are normal in a population with a low likelihood of CHD, defined clinically. Normalcy has been reported in a number of studies (Table 5) and the weighted average of normalcy is $89 \%$.

Another form of referral bias is when mainly highlikelihood patients are referred for MPS, which increases apparent sensitivity because of the higher proportion of patients with more severe disease [75, 83]. Analysis of the tables above shows that mean sensitivity reduces from $92 \%$ to $87 \%$ when studies including patients with prior infarction are excluded. Sensitivity is also higher with more extensive and severe disease and lower with single-vessel disease or in those with stenoses involving branches of the major vessels ( $91 \%$ versus $83 \%$ ).

The intensity of stress is also a confounding factor and several studies have shown that sensitivity is related to the intensity of exercise $[14,23,84]$. Anti-angina medication reduces sensitivity using dynamic exercise $[85,86]$ and medication should ideally be discontinued before diagnostic studies [87]. It is less clear whether medication reduces diagnostic sensitivity using vasodilator stress but reduced sensitivity has been observed [88].

Tracer activity below the diaphragm is commonly seen with MIBI and tetrofosmin and this can reduce accuracy in some studies $[40,45]$. Other causes of artefact that can reduce specificity are photon attenuation and scatter, patient motion, low count statistics, reconstruction artefact or processing errors. Experienced practitioners can normally identify these problems and they maintain sensitivity and specificity not only by recognising common abnormal appearances but also by taking account of the clinical circumstances. Thus, studies where images are interpreted in the absence of clinical information can lead to relatively poor diagnostic performance [73]. Image quantification can help inter-observer variability but its value for accuracy is less clear, with some studies showing greater accuracy with quantification $[11,32,47]$ and others no difference $[12,16,17,28$, 83]. Correction for photon attenuation and scatter, using simultaneous or sequential transmission imaging, is also now feasible but its value is not yet clearly established $[89,90,91,92,93]$.

ECG-gating is another option that improves diagnostic accuracy and it is now used routinely in many centres. This aids the distinction between true perfusion abnormality and artefact $[94,95,96]$ and it provides additional prognostic information from global and regional left ventricular function [97].

Despite their different physical and imaging characteristics, all three radiotracers have comparable diagnostic accuracies for detecting CAD. This can be seen in the above tables and it has been confirmed clinically in a large randomised study (the ROBUST study) [55]. However, the technetium-99m labelled tracers have myocardial uptake curves that plateau at lower levels of hyperaemia than thallium, and it has been suggested that they may not perform well when used with vasodilator stress [98]. However, several studies with MIBI indicate that diagnostic accuracy is not compromised with vasodilators [36, 41, 42, 43, 44, 52, 53]. Studies using tetrofosmin with vasodilator stress are less consistent, with some reporting good diagnostic accuracy [55] and others 
Table 6. Prognostic value of MPS in definite or suspected CHD (adapted from reference [111])

\begin{tabular}{|c|c|c|c|c|c|c|c|c|c|}
\hline Year & Author [ref.] & No. & Agent & $\begin{array}{l}\text { Abnormal } \\
\text { MPS (\%) }\end{array}$ & $\begin{array}{l}\text { Mean } \\
\text { F/U (m) }\end{array}$ & $\begin{array}{l}\mathrm{HE} \\
(\% / \mathrm{yr})\end{array}$ & $\begin{array}{l}\text { HE with } \\
\text { abnormal } \\
\text { MPS (\%/yr) }\end{array}$ & $\begin{array}{l}\text { HE with } \\
\text { normal } \\
\text { MPS }(\% / y r)\end{array}$ & $\mathrm{RR}$ \\
\hline 2001 & Galassi [113] & 459 & Tetro & 77 & 37 & 2.5 & 3.0 & 0.9 & 3.25 \\
\hline 1999 & Vanzetto [114] & 1,137 & $201 \mathrm{Tl}$ & 66 & 72 & 1.5 & 2.0 & 0.6 & 3.53 \\
\hline 1998 & Hachamovitch [108] & 5,183 & $\mathrm{MIBI} / 201 \mathrm{Tl}$ & 43 & 21.4 & 3.0 & 5.9 & 0.8 & 7.50 \\
\hline 1998 & Olmos [115] & 225 & ${ }^{201} \mathrm{Tl}$ & 49 & 44.4 & 1.8 & 2.7 & 0.9 & 2.86 \\
\hline 1998 & Alkeylani [116] & 1,086 & MIBI & 62 & 27.6 & 3.4 & 5.0 & 0.6 & 8.92 \\
\hline 1997 & Snader [117] & 3,400 & ${ }^{201} \mathrm{Tl}$ & 21 & $\sim 24$ & $1.6(\mathrm{ACM})$ & $\sim 3.8(\mathrm{ACM})$ & $\sim 1.0(\mathrm{ACM})$ & 3.75 \\
\hline 1997 & Boyne [118] & 229 & MIBI & 32 & 19.2 & 2.2 & 5.1 & 0.8 & 6.23 \\
\hline 1997 & Geleijnse [119] & 392 & MIBI & 67 & 22 & 6.0 & 8.7 & 0.8 & 10.67 \\
\hline 1995 & Heller [120] & 512 & MIBI & 58 & 12.8 & 4.6 & 6.9 & 1.3 & 5.29 \\
\hline 1994 & Machecourt [121] & 1,926 & ${ }^{201} \mathrm{Tl}$ & 63 & 33 & 2.0 & 2.9 & 0.5 & 6.23 \\
\hline 1994 & Kamal [122] & 177 & ${ }^{201} \mathrm{Tl}$ & 83 & 22 & 4.3 & 5.2 & 0 & - \\
\hline 1994 & Stratmann [123] & 534 & MIBI & 66 & 13 & 10.1 & 14.3 & 1.6 & 9.12 \\
\hline 1994 & Stratmann [124] & 521 & MIBI & 60 & 13 & 4.2 & 6.7 & 0.5 & 14.60 \\
\hline
\end{tabular}

ACM, All-cause mortality; HE, hard event (cardiac death or non-fatal MI); RR, relative risk; other abbreviations as defined in Table 1 and list of abbreviations

showing reduced sensitivity in patients with mild disease $[31,99]$. Reduced sensitivity has also been reported in some but not all studies of MIBI performed with dobutamine $[69,72]$.

\section{Overall accuracy of MPS}

In summary, therefore, despite the availability of three different tracers, several forms of stress and the confounding factors described above, it is reasonable for the purposes of this appraisal to consider MPS as a generic test without regard for the different ways in which it can be performed. When this is done, good quality studies show a sensitivity for CHD defined angiographically as high as $90 \%$ and a normalcy of $89 \%$.

\section{Prognosis}

\section{MPS and prognosis}

For many patients with CHD, the assessment of prognosis, or likelihood of future cardiac events, is an essential step in choosing between medical management and revascularisation. The power of MPS for predicting future coronary events has been demonstrated in a large number of high-quality studies and in many thousands of patients. It is perhaps the area of nuclear cardiology where the evidence is most strong [100, 101, 102].

The most important variables that predict the likelihood of future events are the extent and severity of inducible ischaemia [103] but other predictors are increased lung uptake of thallium [104], stress-induced ventricular dilatation[105] and left ventricular ejection fraction [106,
107]. In general, markers of left ventricular dysfunction tend to predict cardiac mortality and inducible ischaemia predicts acute coronary syndromes [108, 109]. MPS has incremental prognostic value even after clinical assessment, exercise electrocardiography and coronary angiography $[97,110]$. In other words, patients who appear to be high risk after coronary angiography can be separated into higher and lower risk groups by MPS.

Patients with abnormal MPS have on average an annual event rate (cardiac death or myocardial infarction) of $6.7 \%$ (Table 6). In contrast, it is an almost universal finding that normal MPS indicates good clinical outcome, irrespective of other features such as the presence of non-obstructive coronary disease. Thus 16 studies performed between 1994 and 2001, which reported 20,983 patients with normal MPS and a mean follow-up of 28 months, showed a rate of cardiac death or myocardial infarction of $0.7 \%$ per year, a rate similar to that of an asymptomatic population (Table 7) [111]. Similar findings have recently been reported in a multicentre registry of 4,728 patients [112]. Thus, whether minor coronary artery disease is present or not, further investigation can be avoided.

Patients with chest pain and a normal resting ECG who are able to exercise will often undergo exercise electrocardiography as the initial test for diagnosis and risk stratification. Intermediate risk results, however, occur in approximately $30-55 \%$ cases $[128,179]$ and it is in these patients that perfusion imaging has its greatest role. It has incremental prognostic value within this risk category, and there is a closer association of subsequent coronary angiographic data with the results of the perfusion scan than with the exercise electrocardiogram [126].

When the resting ECG is abnormal, exercise testing can provide some prognostic information from the exer- 
Table 7. Prognostic value of normal MPS in patients presenting with stable chest pain (adapted from reference [111])

\begin{tabular}{|c|c|c|c|c|c|c|}
\hline Year & Author [ref.] & No. & Agent & $\begin{array}{l}\text { Normal MPS } \\
(\%)\end{array}$ & $\begin{array}{l}\text { Mean F/U } \\
\text { (months) }\end{array}$ & $\begin{array}{l}\text { HE with } \\
\text { normal MPS } \\
\text { (\% per yr) }\end{array}$ \\
\hline 2001 & Galassi [113] & 459 & Tetro & 23 & 37 & 0.9 \\
\hline 2000 & Groutars [125] & 236 & Tetro/201Tl & 100 & 25 & 0.4 \\
\hline 1999 & Gibbons [126] & 4,473 & 201Tl/MIBI & 100 & 36 & 0.6 \\
\hline 1999 & Soman [127] & 473 & MIBI & 100 & 30 & 0.2 \\
\hline 1999 & Vanzetto [114] & 1,137 & ${ }^{201} \mathrm{Tl}$ & 34 & 72 & 0.6 \\
\hline 1998 & Hachamovitch [108] & 5,183 & $\mathrm{MIBI} / 201 \mathrm{Tl}$ & 57 & 21.4 & 0.8 \\
\hline 1998 & Olmos [115] & 225 & ${ }^{201} \mathrm{Tl}$ & 51 & 44.4 & 0.9 \\
\hline 1998 & Alkeylani [116] & 1,086 & MIBI & 38 & 27.6 & 0.6 \\
\hline 1997 & Snader [117] & 3,400 & ${ }^{201} \mathrm{Tl}$ & 79 & $\sim 24$ & $\sim 1.0(\mathrm{ACM})$ \\
\hline 1997 & Boyne [118] & 229 & MIBI & 68 & 19.2 & 0.8 \\
\hline 1997 & Geleijnse [119] & 392 & MIBI & 33 & 22 & 0.8 \\
\hline 1995 & Heller [120] & 512 & MIBI & 42 & 12.8 & 1.3 \\
\hline 1994 & Machecourt [121] & 1,926 & ${ }^{201} \mathrm{Tl}$ & 37 & 33 & 0.5 \\
\hline 1994 & Kamal [122] & 177 & ${ }^{201} \mathrm{Tl}$ & 17 & 22 & 0 \\
\hline 1994 & Stratmann [123] & 534 & MIBI & 34 & 13 & 1.6 \\
\hline \multirow[t]{2}{*}{1994} & Stratmann [124] & 521 & MIBI & 40 & 13 & 0.5 \\
\hline & Total & 20,963 & & 53 & 28.3 & 0.7 \\
\hline
\end{tabular}

ACM, All-cause mortality; HE, hard event (cardiac death or non-fatal MI); RR, relative risk; other abbreviations as defined in Table 1 and list of abbreviations

cise duration but ECG changes are unhelpful. In contrast, MPS maintains its prognostic power [130].

Prognosis can be assessed in patients who are unable to exercise using MPS with pharmacological stress. The risk of cardiac death in these patients is higher than in patients able to exercise, most likely because of higher underlying likelihood of disease [131].

\section{MPS as the gatekeeper to angiography}

Because of its prognostic power, MPS can be used as the gatekeeper to coronary angiography. Bateman and colleagues showed that referral to coronary angiography after normal, mild to moderately abnormal and severely abnormal perfusion scans was $3.5 \%, 9 \%$ and $60 \%$ respectively [132]. Importantly, a policy of selective referral to coronary angiography based upon high-risk findings is defensible, patients with mild to moderate abnormalities managed medically having outcomes comparable to those undergoing invasive evaluation and subsequent angioplasty [133].

\section{Risk assessment before non-cardiac surgery}

MPS can provide useful information about cardiac risk in patients requiring non-cardiac surgery although these patients are generally at low risk and the predictive value of a normal perfusion study is greater than that of an abnormal study. In a meta-analysis of 3,718 patients under- going vascular and other surgery, the positive predictive value of inducible ischaemia for peri-operative death or infarction was $12.9 \%$ compared with a negative predictive value of $98.6 \%$, a risk ratio of 9.1 (Table 8).

The ACC/AHA algorithm for pre-operative risk assessment considers initially the urgency for surgery, its inherent cardiac risk, the patient's risk factors and exercise tolerance [134]. Patients with only minor clinical predictors (advanced age, abnormal resting ECG, previous stroke or uncontrolled hypertension) who require low- to moderate-risk surgery are at low risk and do not require further investigation. Patients with intermediate clinical predictors (mild angina, prior infarction, treated heart failure or diabetes) or with minor predictors and reduced exercise tolerance need further assessment before moderate- or high-risk surgery. Patients at high clinical risk (recent infarction or unstable angina, uncontrolled heart failure or significant arrhythmias) require investigation before any sort of surgery. When further investigation is required, the choice lies primarily between the exercise ECG and MPS, the latter usually being reserved for patients with an abnormal resting ECG or who are unable to exercise. In general, patients identified as low risk can undergo surgery without further investigation. All other patients require aggressive medical management at the time of surgery, intervention usually being reserved for those in whom revascularisation is indicated regardless of the need for surgery. 
Table 8. MPS for preoperative assessment of cardiac risk (adapted from reference [134])

\begin{tabular}{|c|c|c|c|c|c|}
\hline Year & Author [ref.] & No. & $\begin{array}{l}\text { Inducible } \\
\text { ischaemia } \\
(\%)\end{array}$ & $\begin{array}{l}\text { MI/death } \\
(\%)\end{array}$ & PPV \\
\hline
\end{tabular}

\begin{tabular}{|c|c|c|c|c|c|c|}
\hline \multicolumn{7}{|c|}{ Vascular surgery } \\
\hline 1985 & Boucher [135] & 48 & $16(33)$ & $3(6 \%)$ & $19 \%(3 / 16)$ & $100 \%(32 / 32)$ \\
\hline 1987 & Cutler [136] & 116 & $54(47)$ & $11(10 \%)$ & $20 \%(11 / 54)$ & $100 \%(60 / 60)$ \\
\hline 1988 & Fletcher [137] & 67 & $15(22)$ & $3(4 \%)$ & $20 \%(3 / 15)$ & $100 \%(56 / 56)$ \\
\hline 1988 & Sachs [138] & 46 & $14(31)$ & $2(4 \%)$ & $14 \%(2 / 14)$ & $100 \%(24 / 24)$ \\
\hline 1989 & Eagle [139] & 200 & $82(41)$ & $15(8 \%)$ & $16 \%(13 / 82)$ & $98 \%(61 / 62)$ \\
\hline 1990 & McEnroe [140] & 95 & $34(36)$ & $7(7 \%)$ & $9 \%(3 / 34)$ & $96 \%(44 / 46)$ \\
\hline 1990 & Younis [141] & 111 & $40(36)$ & $8(7 \%)$ & $15 \%(6 / 40)$ & $100 \%(51 / 51)$ \\
\hline 1991 & Mangano [142] & 60 & $22(37)$ & $3(5 \%)$ & $5 \%(1 / 22)$ & $95 \%(19 / 20)$ \\
\hline 1991 & Strawn [143] & 68 & $\mathrm{n} / \mathrm{a}$ & $4(6 \%)$ & $\mathrm{n} / \mathrm{a}$ & $100 \%(21 / 21)$ \\
\hline 1991 & Watters [144] & 26 & $15(58)$ & $3(12 \%)$ & $20 \%(3 / 15)$ & $100 \%(11 / 11)$ \\
\hline 1992 & Hendel [145] & 327 & $167(51)$ & $28(9 \%)$ & $14 \%(23 / 167)$ & $99 \%(97 / 98)$ \\
\hline 1992 & Lette [146] & 355 & $161(45)$ & $30(8 \%)$ & $17 \%(28 / 161)$ & $99 \%(160 / 162)$ \\
\hline 1992 & Madsen [147] & 65 & $45(69)$ & $5(8 \%)$ & $11 \%(5 / 45)$ & $100 \%(20 / 20)$ \\
\hline 1993 & Brown [148] & 231 & $77(33)$ & $12(5 \%)$ & $13 \%(10 / 77)$ & $99 \%(120 / 121)$ \\
\hline 1993 & Kresowik [149] & 170 & 67 (39) & $5(3 \%)$ & $4 \%(3 / 67)$ & $98 \%(64 / 65)$ \\
\hline 1994 & Baron [150] & 457 & $160(35)$ & $22(5 \%)$ & $4 \%(7 / 160)$ & $96 \%(195 / 203)$ \\
\hline 1994 & Bry $[151]$ & 237 & $110(46)$ & $17(7 \%)$ & $11 \%(12 / 110)$ & $100 \%(97 / 97)$ \\
\hline 1995 & Koutelou [152] & 106 & $47(44 \%)$ & $3(3 \%)$ & $6 \%(3 / 47)$ & $100 \%(49 / 49)$ \\
\hline 1995 & Marshall [153] & 117 & $55(47 \%)$ & $12(10 \%)$ & $16 \%(9 / 55)$ & $97 \%(33 / 34)$ \\
\hline 1997 & Van Damme [154] & 142 & $48(34 \%)$ & $3(2 \%)$ & $\mathrm{n} / \mathrm{a}$ & $\mathrm{n} / \mathrm{a}$ \\
\hline \multicolumn{7}{|c|}{ Non-vascular surgery } \\
\hline 1990 & Camp [155] & 40 & $9(23)$ & $6(15 \%)$ & $67 \%(6 / 9)$ & $100 \%(23 / 23)$ \\
\hline 1991 & Iqbal [156] & 31 & $11(41)$ & $3(11 \%)$ & $27 \%(3 / 11)$ & $100 \%(20 / 20)$ \\
\hline 1992 & Coley [157] & 100 & $36(36)$ & $4(4 \%)$ & $8 \%(3 / 36)$ & $98 \%(63 / 64)$ \\
\hline 1992 & Shaw [158] & 60 & $28(47)$ & $6(10 \%)$ & $21 \%(6 / 28)$ & $100 \%(19 / 19)$ \\
\hline 1993 & Takase [159] & 53 & $15(28)$ & $6(11 \%)$ & $27 \%(4 / 15)$ & $100 \%(32 / 32)$ \\
\hline 1994 & Younis [160] & 161 & $50(31)$ & $15(9 \%)$ & $18 \%(9 / 50)$ & $98 \%(87 / 89)$ \\
\hline \multirow[t]{2}{*}{1996} & Stratmann [161] & 229 & $67(29 \%)$ & $10(4 \%)$ & $6 \%(4 / 67)$ & $99 \%(91 / 92)$ \\
\hline & Weighted average & 3,718 & & $246(7 \%)$ & $12.1 \%(186 / 1,397)$ & $98.6 \%(1,549 / 1,571)$ \\
\hline
\end{tabular}

MI, Myocardial infarction; NPV, negative predictive value; PPV, positive predictive value; n/a, not available

\section{Special groups}

\section{Women}

Cardiovascular disease is the commonest cause of death in women in Europe [162]. Underlying mechanisms are complex, although increasing prevalence of risk factors and greater life expectancy play an important role. The prevalence of risk factors is higher in women than in men, and triglycerides, HDL-cholesterol, cigarette smoking and diabetes are particularly important [163]. In addition to the obvious hormonal influences in women, there are gender-related structural differences in plaque composition (more cellular fibrous tissue) [164] and incidence of sub-clinical atherosclerosis [165]. These factors may explain, in part, why women present with symptoms some 10 years later than men, are less likely to complain of chest pain and are more likely to suffer upper abdominal pain, dyspnoea, nausea and fatigue.

\section{Diagnosis}

In men, the exercise ECG is the conventional gatekeeper for invasive investigation and possible intervention when assessing known or potential CHD. In women, however, the exercise ECG has at best only moderate accuracy for the detection of CHD [166]. In contrast, MPS is equally accurate for the detection of disease in women and men [167].

\section{Prognosis}

Although initial prognostic data were acquired for largely male populations aged less than 70 years, recent studies have established that the prognostic power of normal and abnormal myocardial perfusion images is equally strong in men and women. In fact women with severe abnormalities may have a worse outcome than men with 
severe abnormalities. In a study of 1,394 women followed for a mean of 20 months, MPS was able to stratify women according to risk irrespective of presenting likelihood of CHD [168]. In a further study of 3,402 women, normal MPS predicted a favourable outcome and the extent of inducible ischaemia was strongly associated with mortality [169]. Three-year survival reduces from 99\% to $85 \%$ as the number of vascular territories with perfusion abnormality increases from zero to three [170]. This prognostic power is additional to clinical information and information from the exercise ECG [20, 168, 171, 172].

Acute myocardial infarction

Women with acute myocardial infarction have an increased probability of surviving to reach hospital but they have a higher mortality at 30 days than men [173]. MPS is helpful for triage in the general population presenting with acute chest pain but there are few data on MPS in this setting in women [174].

\section{The elderly}

An ageing population leads to increasing use of NHS resources. Because the elderly have reduced capacity for exercise and frequently have abnormal resting ECGs, the exercise ECG is of limited use [175] but MPS using pharmacological stress is effective and it retains its diagnostic and prognostic power $[176,177$, 178, 179].

\section{Diabetes}

Diabetes is a vascular disease. Type 2 diabetes is associated with the same cluster of risk factors as cardiovascular disease and life expectancy is reduced by $8-10$ years in the 40- to 70-year age group. Type 1 diabetes carries the same mortality even though it is not associated with the same risk factors [180].

Several studies have demonstrated the prognostic power of MPS in diabetic patients [181, 182, 183]. In a study of 1,371 patients, normal MPS was associated with an incidence of cardiovascular events of $1-2 \%$ per year, while the incidence was greater than $7 \%$ per year in those with severe perfusion abnormalities [184]. Multivariate analysis has shown that MPS abnormalities, retinopathy and duration of diabetes are independent predictors of cardiac events [185]. It has been suggested that MPS might be used to screen for CHD in high-risk asymptomatic diabetics, and a multicentre clinical trial to evaluate the effectiveness of this approach is in progress [186].

\section{Ethnicity}

South Asians resident in the UK have a 40-50\% higher mortality from CHD than the population average, the reason for which is not clearly defined. MPS is equally effective in South Asians and Afro-Caribbeans for the diagnosis of CHD and assessment of prognosis, although account should be taken of the different CHD profiles $[187,188,189]$.

\section{Revascularisation}

\section{Before revascularisation}

MPS is superior to the exercise ECG for the detection of myocardial ischaemia and it provides independent and incremental information in predicting future cardiac events [190, 191]. This applies in almost all clinical circumstances, including suspected CHD, stable angina, after stabilisation of acute coronary syndromes and before non-cardiac surgery. It also applies before and after myocardial revascularisation and hence the technique is valuable in assessing the need for and the outcome of intervention [192].

In patients with ischaemic left ventricular dysfunction, MPS can define the need for revascularisation by determining the presence and extent of ischaemia and of viable but hibernating myocardium [193, 194, 195, 196] (Table 9). This is particularly the case with severe left ventricular dysfunction, when MPS can predict the improvement in left ventricular function and the overall prognosis [181, 197, 198]. MPS is most helpful when left ventricular ejection fraction is severely reduced, and in these high-risk patients rest imaging alone can detect viable myocardium $[199,200,201,202,203$, 204].

\section{After revascularisation}

MPS is more sensitive than the exercise ECG in detecting inducible ischaemia if angina recurs after revascularisation, and it can be used to evaluate the success of revascularisation [205]. It is an accurate technique for detecting bypass graft occlusion or stenosis, with sensitivity and specificity of $81 \%$ and $79 \%$ respectively [206, 207, 208] (Table 10).

Table 9. Indications for MPS before revascularisation

Detection, localisation and quantification of ischaemia as a cause of symptoms

Detection of silent ischaemia

Risk stratification and prognostication

Detection and quantification of viable/hibernating myocardium 
Table 10. Indications for MPS after revascularisation

After percutaneous coronary intervention

Suboptimal results

Recurrence of symptoms or suspected restenosis

Multivessel disease with incomplete revascularisation

Procedural complications

Assessing the effects of intervention if required

for occupational reasons

After coronary artery bypass grafting

Incomplete revascularisation or poor distal vessels

Recurrence of symptoms or suspected graft occlusion

Procedural complications

Assessing the effects of intervention if required

for occupational reasons

Chest pain and exercise electrocardiography are largely unhelpful in identifying patients at risk after revascularisation [209] but MPS is of proven value [197, 208, 210, 211, 212]. In the NIH-sponsored Emory Angioplasty versus Surgery Trial (EAST), inducible perfusion abnormalities 1 year after revascularisation separated the patients into low- and high-risk groups [213]. This prognostic power lasts for a considerable time and the technique is valuable for long-term follow-up [209, 211, 214, 215, 216, 217].

Following percutaneous intervention the situation is more complex. Normal perfusion excludes restenosis and indicates a good prognosis [212] but inducible perfusion abnormalities can be seen in the first 6 weeks after angioplasty in the absence of restenosis and these are thought to correspond to abnormal small vessel or endothelial function [218]. Thereafter an abnormal perfusion study is predictive of adverse cardiac events [219].

\section{Acute coronary syndromes}

Cardiological management of patients with acute coronary syndromes (ACS) was an important implication of the National Service Framework for CHD [220]. The joint BCS and RCP guidelines for the management of ACS without persistent ST segment elevation [221] have recommended that dedicated units for the assessment of low-risk patients with acute chest pain should be evaluated based upon evidence from the USA [222] and the UK [223]. High-risk patients, including those with raised troponin, persistent symptoms and/or ST segment changes or adverse exercise ECG results, should have urgent coronary angiography, with the intention of revascularisation to improve outcome. However, if symptoms settle on medical therapy and there are no clinical markers of high risk, MPS can be used for risk stratification [224, 225]. This concept applies across the spectrum of ACS, from patients without diagnostic ECG changes, to unstable angina (UA), to non-ST segment elevation myocar-

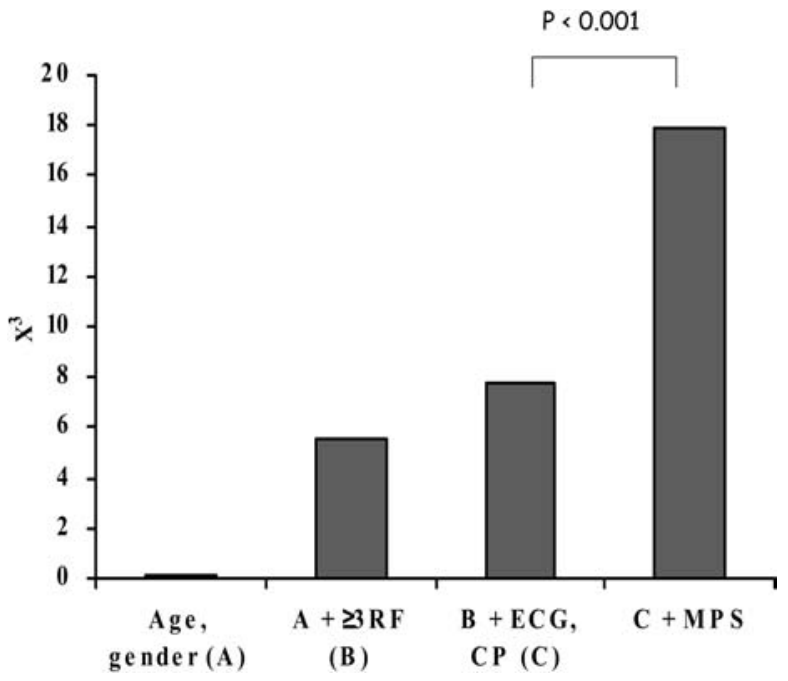

Fig. 1. The incremental value of resting MPS to predict cardiac events in emergency department patients with suspected ACS. Chi-square (y-axis) measures the strength of the association between individual factors added in incremental fashion (x-axis) and unfavourable cardiac events. $R F$, Risk factors; $\mathrm{CP}$, chest pain. (Adapted from reference [232])

dial infarction (NSTEMI) and to ST segment elevation myocardial infarction (STEMI). Risk assessment, together with appropriate aggressive secondary prevention, is particularly helpful in the UK situation of uneven access to revascularisation, and allows for appropriate prioritisation of patients.

\section{Imaging in the emergency department}

\section{Relationship of imaging and clinical outcome}

There is a substantial body of literature evaluating rest MPS in patients presenting with acute chest pain and suspected ACS. When tracer is injected during pain, MPS has $96 \%$ sensitivity for severe coronary stenosis compared with 35\% sensitivity for the resting ECG [226] and as much as $20 \%$ of the myocardium can be abnormal when the ECG is normal or non-diagnostic [227]. Patients with abnormal MPS have a substantially higher likelihood of adverse cardiac events during hospitalisation and follow-up (Fig. 1) [228]. Conversely, MPS has a negative predictive value for ruling out myocardial infarction of $99 \%$ or more in all studies (Fig. 2) [228, 229, 230]. Consequent reduction in the missed infarction rate from $1.8 \%$ to $0.1 \%$ has important implications for patient outcome and the cost-effectiveness of management [231, 232]. 


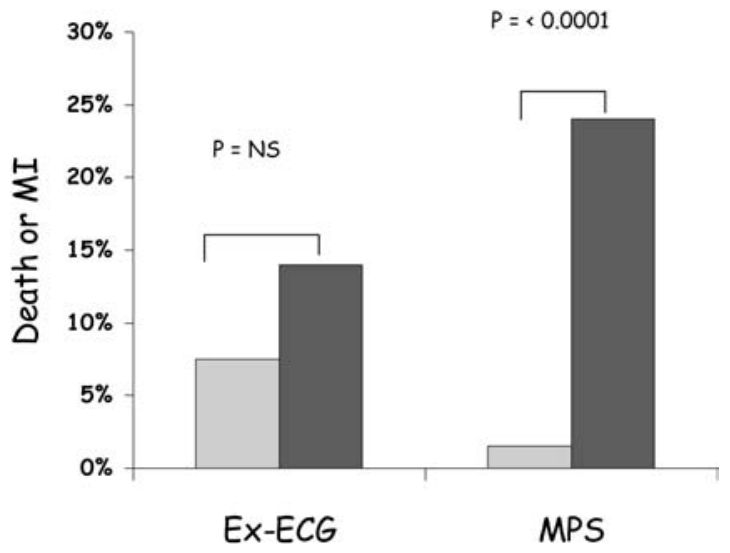

Fig. 2. The predictive value for death and infarction after initial stabilisation of unstable angina with medical therapy, according to whether the exercise ECG (Ex-ECG) is negative (light grey) or positive (dark grey) and whether MPS does not (light grey) or does (dark grey) show inducible ischaemia. Summary of three studies adapted from reference [238]

Comparison with enzymatic markers

of myocardial damage

Acute MPS has the potential to identify ACS much earlier in its evolution than enzyme markers, with an early sensitivity for myocardial infarction of $92 \%$ compared with only $39 \%$ for troponin I assayed at the same time [233].

\section{Randomised trials}

Two randomised controlled trials have shown that MPS can improve triage decisions in the emergency department. Stowers and colleagues randomised 46 patients with acute chest pain and non-diagnostic ECGs to an MPS-guided strategy or conventional care; the former incurred less cost, shorter hospital and intensive care stays, and fewer cardiac catheterisations but there was no difference in outcome at 30 days [234]. The ERASE trial (Emergency Room Assessment of Sestamibi for Evaluation of Chest Pain) randomised 2,127 similar patients to similar strategies and showed fewer admissions of patients shown ultimately not to have ACS (20\% reduction, odds ratio $0.68, P<0.001$ ) [235]. This benefit applied independently of age, gender, risk factors or imaging experience.

\section{Suspected acute myocardial infarction}

The impetus for chest pain assessment units in an emergency admissions area is supported by the fifth joint report of the RCP and BCS on provision of cardiothoracic services [236].
Non-ST segment elevation myocardial infarction and unstable angina

There is general agreement that the half of the patients with UA and high-risk clinical features should undergo prompt coronary angiography, but there is less agreement on the management of the other half who are at intermediate or low clinical risk, as originally defined by the US Agency for Health Care and Policy Research Guidelines [237]. MPS is known to be able to separate these patients into a low-risk group that might be managed conservatively without angiography and a higher risk group that might benefit from intervention, and recent randomised trials support this strategy [238]. Accordingly, MPS in this setting is a class 1 indication under AHA/ACC guidelines [234].

The main benefit of intervention in ACS in RITA 3 was in reducing refractory angina, which could have been identified by a conservative strategy [239], and a recent meta-analysis has suggested no clear superiority of early intervention [240]. These data therefore suggest that a conservative strategy in which stabilised patients are risk-stratified by MPS offers similar outcomes with fewer invasive procedures. This concept is relevant for UK practice and the use of MPS as a gatekeeper to angiography in stabilised ACS might reduce the trend towards diminishing marginal returns of early invasive management.

A recent retrospective analysis of the TIMI-IIIB data has shown that a simple clinical score is able to classify over half the population as low risk [241], suggesting a substantial group of patients in whom MPS might be used for further risk stratification. In TACTICSTIMI18, the troponin positive subgroup (60\% of the total population) had a larger reduction in death or myocardial infarction with the early invasive strategy, leaving $40 \%$ who might benefit from non-invasive risk stratification using MPS [242]. The UK guidelines [221] suggest a conservative strategy even for patients with an abnormal troponin providing that symptoms have settled for $48 \mathrm{~h}$ and there are no other high-risk features.

\section{ST segment elevation myocardial infarction}

The majority of patients who survive the initial acute stage of myocardial infarction will have a relatively stable course, and current guidelines recommend non-invasive risk assessment before hospital discharge [243, 244]. MPS with vasodilator stress can be performed safely as early as 3 days after infarction, before the majority of recurrent clinical events occur, and can be used to guide early discharge [245]. ECG-gated imaging also provides a measure of left ventricular function, which has additional value in predicting outcome (Fig. 3) [246]. Coronary angiography does not improve a prog- 


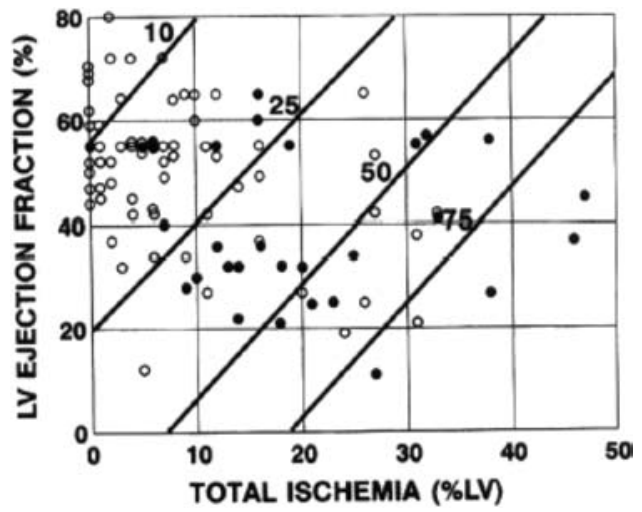

Fig. 3. Cox regression models displaying 1-year post-infarction risk of cardiac event according to LV ejection fraction and total LV ischaemia. Diagonal lines, Lines of equal risk. Risk increases as total LV ischaemia increases and LV ejection fraction decreases. LV ejection fraction and scintigraphic results for each of 92 patients who did (solid circles) or did not (open circles) have subsequent cardiac events over the entire follow-up period are plotted against calculated risk at 1 year. (From reference [246])

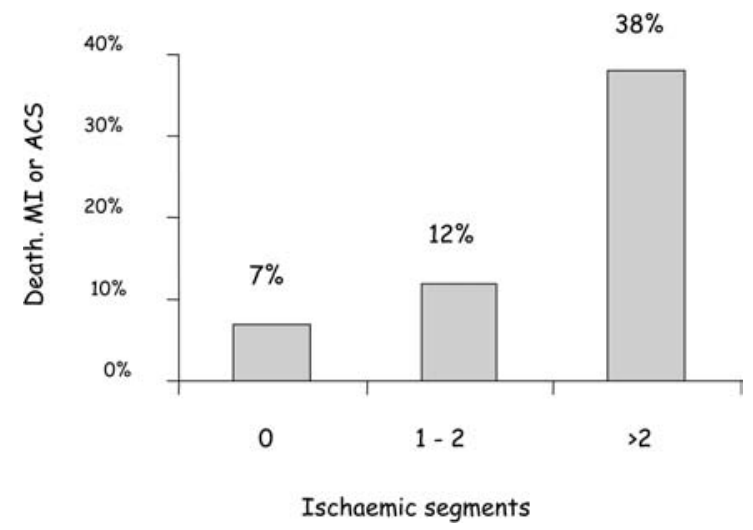

Fig. 4. Hard event rates over a mean of 15 months after myocardial infarction according to the number of segments with inducible ischaemia by MPS. Patients with more extensive ischaemia are at progressively higher risk $(P=0.017)$. (From reference [248])

nostic model that includes clinical, ejection fraction and MPS data [247].

Travin and colleagues used MPS in 134 patients within 14 days of uncomplicated infarction and showed that the extent of ischaemia was the only significant predictor of future cardiac events on Cox regression analysis (Fig. 4) [248]. Similarly, Basu and colleagues in the UK showed a hazard ratio of 8.1 (95\% CI 2.7-23.8, $P<0.001)$ for coronary events comparing patients with and without inducible perfusion abnormalities [249]. Patients with no evidence of inducible ischaemia within the infarct zone, even in the presence of residual stenosis of the infarct-related artery, were found by Ellis and colleagues to derive no benefit from angioplasty [250].

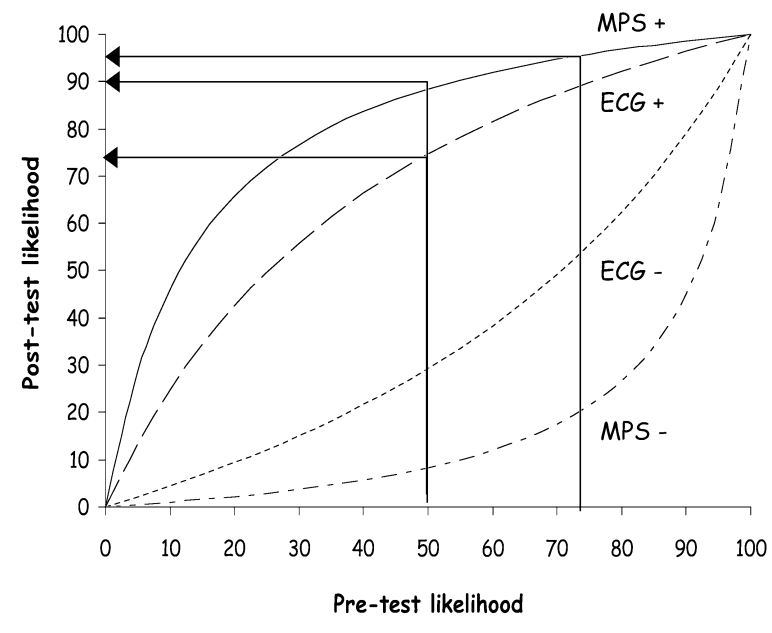

Fig. 5. Pre- and post-test likelihood of CHD calculated using Bayesian principles for the exercise ECG and MPS, using sensitivities of $68 \%$ and $92 \%$ respectively and specificities of $77 \%$ and $88 \%$ respectively. The curved lines from top to bottom represent MPS+, ECG+, ECG- and MPS-

Table 11. Principles of cost-effective diagnosis and management of CHD using MPS

High sensitivity excludes disease more accurately and avoids the need for a secondary test that could arise if a less accurate primary test were used

High sensitivity leads to fewer false negative tests and avoids the cost of future events in undiagnosed patients with disease

High specificity reduces the number of false positive tests and consequent downstream testing

Additional prognostic information avoids the need for further prognostic testing and focusses high-cost interventional care on patients with advanced disease and with most to gain in terms of clinical outcome

\section{Cost-effectiveness}

Several principles underlie why a more accurate diagnostic test with additional prognostic information, such as MPS, can be more cost-effective even if it is more expensive than an alternative test such as the exercise ECG (Table 11) [251].

For instance, Fig. 5 illustrates that when a patient with a presenting likelihood of CHD of 50\% has an abnormal exercise ECG the post-test likelihood of disease is $73 \%$, which is not sufficiently high to be confident of the diagnosis. A subsequent abnormal MPS gives a likelihood of $96 \%$ but if the same patient had gone directly to MPS the post-test likelihood would have been $90 \%$, which should be sufficiently high to diagnose the presence of CHD, depending upon the clinical circumstances. 
Table 12. Cost of common diagnostic tests calculated using principles that estimate the true consumption of resources. Estimates are shown for the UK (EMPIRE study) [252] and the USA [253]

\begin{tabular}{|c|c|c|c|}
\hline & $\begin{array}{l}\text { EMPIRE } \\
(£)\end{array}$ & $\begin{array}{l}\text { USA average } \\
\text { (£) }\end{array}$ & 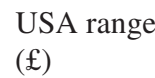 \\
\hline Rest ECG & 20 & & \\
\hline Exercise ECG & 70 & & \\
\hline Rest echocardiography & 100 & 55 & 39-207 \\
\hline $\mathrm{CT}$ & & 172 & $55-288$ \\
\hline MPS & 220 & 179 & $159-348$ \\
\hline MRI & & 529 & $318-739$ \\
\hline PET & & 771 & $582-891$ \\
\hline Coronary angiography & 1,100 & 1,097 & $516-2,873$ \\
\hline
\end{tabular}

CT, Computed X-ray tomography; MPS, myocardial perfusion scintigraphy; MRI, magnetic resonance imaging; PET, positron emission tomography

\section{Costs}

True costs, reflecting consumption of resources, are difficult to estimate. Some analyses of cost-effectiveness have used prices as a surrogate for cost, which may be valid from the perspective of the patient or referring clinician, but is less helpful from the perspective of the healthcare provider. Two studies have estimated cost, one using UK figures [252] and the other USA figures [253], but the findings are similar, at $£ 220$ in the UK and $£ 179$ (range $£ 159-348$ ) in the USA (Table 12). These costings are sensitive to throughput. A reasonable throughput per camera is 2,000 patients per year but this can be increased to as much as 4,000 in high-volume centres by running the camera $12 \mathrm{~h}$ per day and 6 days per week.

\section{Cost-effectiveness analysis}

Although randomised controlled and blinded trials are often used to evaluate the cost-effectiveness of therapy, this study design is difficult or impossible in the case of diagnostic testing. However, some data have been derived from decision analytical models and these have demonstrated the cost-effectiveness of MPS both in patients presenting with stable chest pain syndromes [254] and in pre-operative risk assessment [255]. Garber and Solomon showed that in 55-year-old men presenting with chest pain, a strategy of MPS proceeding to angiography compared with exercise ECG proceeding to angiography cost $£ 25,000$ per quality-adjusted life-year (QALY) [256], a figure that is generally regarded as acceptable [257]. The benefit of MPS would have been even greater if a more realistic model had been used, since it was assumed that all patients with disease proceed to angiography, whereas, as demonstrated above, it is possible to treat low-risk patients with $\mathrm{CHD}$ without the need for angiography. Patterson et al. also found initial testing with MPS to be more cost-effective than the

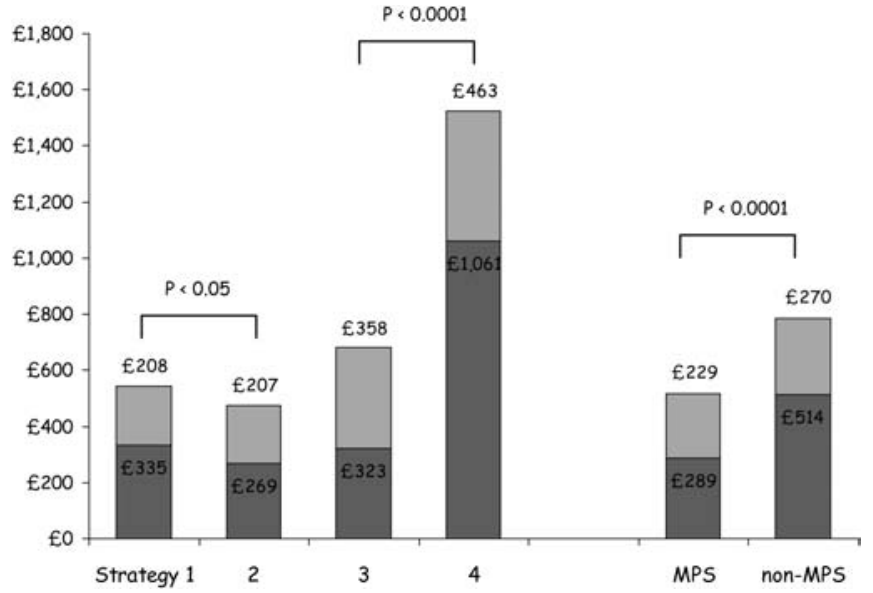

Fig. 6. The 2-year costs of diagnosis (dark grey) and management (light grey) in patients without CHD but presenting with stable chest pain syndromes, according to strategy of investigation and type of hospital. The strategies of investigation are: 1, exECG-angio; 2, exECG-MPS-angio; 3, MPS-angio; 4, angio. MPS, Regular user of MPS; non-MPS, occasional user of MPS. [252]

exercise ECG although, again, the model assumed that all patients with disease undergo angiography [258]. Kuntz found a higher incremental cost-effectiveness of initial MPS over the exercise ECG of $£ 34,250$ in a 55year-old man with atypical chest pain but they used an unrealistically low specificity of $64 \%$ for MPS and again assumed that all patients with disease undergo angiography [259]. It would be valuable to repeat these models assuming that patients with abnormal but low-risk noninvasive tests are treated medically in the first instance, since the prognostic power of MPS is likely to lead to even greater cost-effectiveness.

Interpretation of these numbers should be placed in the context of other generally accepted medical interventions. For example, coronary artery bypass grafting for patients with triple-vessel coronary artery disease and severely impaired left ventricular function costs $£ 25,500$ per QALY gained [260] and cholesterol-lowering therapy in a 60-year-old man with cholesterol of $7.5 \mathrm{mmol} / \mathrm{l}$ costs approximately $£ 30,000$ per QALY [261]. Thus, MPS appears to be a cost-effective use of resources compared with other generally accepted medical procedures.

Mathematical simulations have the advantage of using data from diverse sources or from expert opinion, but they are limited by a lack of real-world effectiveness data. However, two controlled clinical studies have demonstrated savings for similar outcomes using MPS in patients presenting with chest pain. The EMPIRE study compared patients presenting with stable chest pain syndromes to centres that routinely use MPS and those that do not in each of four European countries [252]. Diagnostic strategies using MPS were cheaper and equally effective compared with those that did not, both for the costs of diagnosis and for overall 2-year management costs, but patient outcome was the same (Fig. 6). 


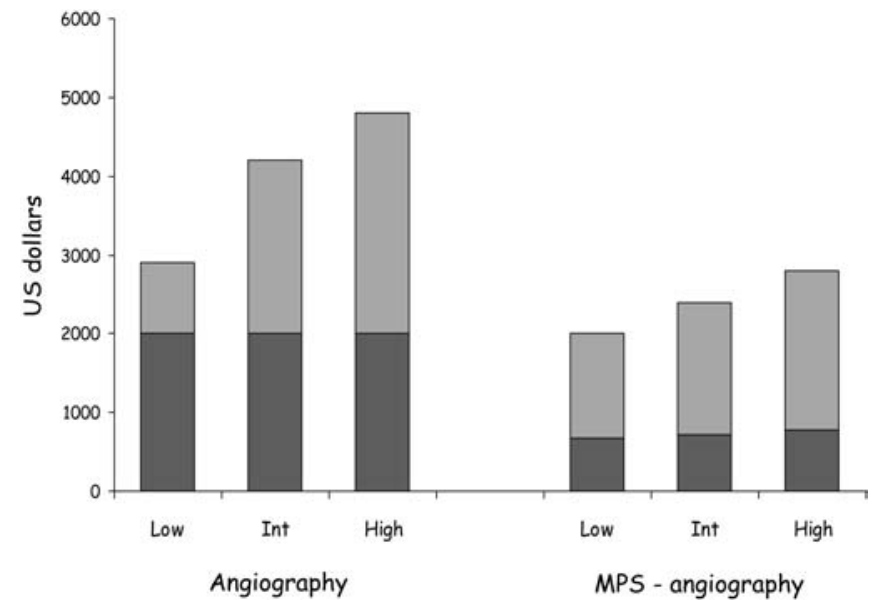

Fig. 7. The 2.5-year costs of diagnosis (dark grey) and management (light grey) in 11,372 patients presenting with stable chest pain syndromes who underwent initial angiography or MPS with selective angiography, according to low, intermediate or high pretest likelihood of CHD. [262]

The END study was a larger (11,372 patients) registry study with very similar findings of $30-40 \%$ savings in costs over 2.5 years in patients with stable chest pain syndromes undergoing initial MPS and selective angiography (Fig. 7) [262]. An additional series of 9,521 patients showed that MPS was more cost-effective than stress echocardiography in patients with known CHD and stable chest pain at $\$ 39,347$ per life-year saved [263], and a separate modelling study also found MPS to be more cost-effective than stress echocardiography [264].
Other clinical studies indirectly support the cost-effectiveness of MPS. In a US practice making routine use of MPS, the number of patients with normal MPS proceeding to angiography is $1 \%$ [265], whereas in a UK rapid access chest pain clinic that makes little use of MPS, coronary angiography rates are high and 56\% of coronary angiograms in women are normal [266]. It has been estimated that routine use of MPS in this setting would reduce cost by $£ 65,000$ per year, mainly by reducing the normal coronary angiography rate [267]. Similarly, in the USA it has been estimated that about one-third of referrals to coronary angiography are inappropriate [268].

\section{Clinical outcomes}

Modelling studies indicate that clinical outcome is improved by MPS at a cost per QALY that is acceptable and that life expectancy is increased by between 7 days and 2 years [255]. Because of the scale and nature of the studies that would be required, it has been more difficult to confirm this finding in clinical studies, but in a re-analysis of the END data [262] Shaw and colleagues have shown that testing with initial MPS adds between 1 and 2 years of life [269] and in a separate study they showed that MPS added 0.5 years compared with stress echocardiography [263].

\section{Current clinical guidelines for MPS}

This section reviews some of the current guidelines for the use of MPS in CHD, which in most cases have been based upon a review of the relevant evidence (Table 13).

Table 13. Guideline documents and statements

\begin{tabular}{ll}
\hline Statement & Source \\
\hline American bodies & Reference \\
Guideline update for exercise testing, 2002 & ACC/AHA/ASNC \\
Guidelines for clinical use of cardiac radionuclide imaging & ACC/AHA \\
Guideline update for the management of patients with chronic stable angina, 2002 & ASNC \\
The role of myocardial perfusion imaging in the clinical evaluation of coronary artery disease & [272] \\
in women & ASNC \\
Updated imaging guidelines for nuclear cardiology procedures: part 1 & [273] \\
$\begin{array}{l}\text { European bodies } \\
\text { Management of acute myocardial infarction in patients presenting with ST segment elevation }\end{array}$ & ESC \\
Management of acute coronary syndromes in patients presenting without ST segment elevation & ESC \\
British bodies & {$[274]$} \\
Investigation and management of stable angina: revised guidelines 1998 & [243] \\
National Service Framework for Coronary Heart Disease & {$[275]$} \\
Guidelines for tomographic radionuclide myocardial perfusion imaging & DoH \\
Guideline for the management of acute coronary syndromes without persistent ECG ST & BNCS/BNMS \\
$\quad$ segment elevation & BCS/RCP
\end{tabular}

ACC, American College of Cardiology; AHA, American Heart Association; ASNC, American Society for Nuclear Cardiology; ESC, European Society of Cardiology; BCS, British Cardiac Soci- ety; RCP, Royal College of Physicians; DoH, UK Department of Health; BNCS, British Nuclear Cardiology; BNMS, British Nuclear Cardiology Society 
Table 14. Recommendations for MPS in chronic stable angina or stable chest pain syndromes requiring investigationa

\begin{tabular}{|c|c|c|c|c|}
\hline Body/guidelines & General & Unable to exercise & Abnormal ECG & Women \\
\hline $\begin{array}{l}\text { ACC/AHA stable } \\
\text { angina guidelines } \\
2002[272]\end{array}$ & $\begin{array}{l}\text { Patients with inter- } \\
\text { mediate likelihood } \\
\text { of CHD }(2 \mathrm{~b} / \mathrm{B})\end{array}$ & $\begin{array}{l}\text { Intermediate likelihood } \\
\text { of CHD (1/B) }\end{array}$ & $\begin{array}{l}\text { Intermediate likelihood of CHD } \\
\text { and ECG with pre-excitation }(1 / \mathrm{B}) \text {, } \\
\text { ST depression }(1 / \mathrm{B}) \text {, ventricular } \\
\text { pacing }(1 / \mathrm{C}) \text {, LBBB }(1 / \mathrm{B}) \text {, digoxin } \\
\text { or } \mathrm{LVH} \text { with minor ST change } \\
\text { (2b/B), these ECGs with low } \\
\text { or high likelihood of CHD }(2 \mathrm{~b} / \mathrm{B})\end{array}$ & $\begin{array}{l}\text { Indications for MPS } \\
\text { are similar in men } \\
\text { and women }\end{array}$ \\
\hline
\end{tabular}

$\begin{array}{lll}\begin{array}{l}\text { ASNC updated } \\ \text { imaging guidelines } \\ {[274]}\end{array} & \begin{array}{l}\text { Diagnosis or prognosis } \\ \text { in known/possible } \\ \text { CHD }\end{array} & \begin{array}{l}\text { As per general } \\ \text { recommendations, } \\ \text { but with pharmaco- } \\ \text { logical stress }\end{array} \\ \begin{array}{l}\text { ACC/AHA/ASNC } \\ \text { guidelines for } \\ \text { clinical use of }\end{array} & \begin{array}{l}\text { To identify extent, } \\ \text { site and severity } \\ \text { radionuclide }\end{array} & \begin{array}{l}\text { Pharmacological } \\ \text { stress with MPS } \\ \text { is "appropriate }\end{array} \\ \text { option" }\end{array}$

imaging 2003 [271]

ACC/AHA stress testing guidelines 2002

ASNC consensus on women with IHD

\section{Low or intermediate likelihood of CHD: exercise test with MPS}

Low or intermediate likelihood of CHD: pharmacological stress with MPS

MPS if reduced exercise tolerance

\section{LBBB specifically recommended}

No comment

Vasodilator stress with MPS recognised as optimal (mainly LBBB)

Vasodilator stress for LBBB, paced rhythm, pre-excitation, ST depression (>1 mm)

MPS if abnormal resting ECG

"Alternate test", e.g. thallium scan

Pharmacological MPS
MPS is "logical" test

\section{BNCS/BNMS guidelines for SPET [277] \\ NSF for Coronary Heart Disease Standard \\ BCS/RCP guidelines for the investigation of stable angina [276]}

\begin{abstract}
Assess patients with suspected CHD
\end{abstract}

MPS when diagnosis is uncertain

\section{Submaximal} exercise ECG

ST depression with low-risk CHD

No ST change with high-risk CHD

Equivocal exercise ECG

\begin{abstract}
Abbreviations as defined in Table 13 and the list of abbreviations a $1,2 \mathrm{a}, 2 \mathrm{~b}, 3$ = class of recommendation; A, B, C = level of evidence
\end{abstract}

\section{Diagnosis and assessment of stable chest pain}

The superior diagnostic accuracy of MPS compared with the exercise ECG is widely recognised in the setting of stable chest pain syndromes and chronic stable angina
(Table 14). Both European and American guidelines recommend MPS in patients with an intermediate pre-test likelihood of coronary artery disease. In the UK, the National Service Framework for CHD does not give specific recommendations, although it does comment on spe- 
Table 15. Recommendations for MPS with respect to revascularisation

\begin{tabular}{ll}
\hline Body & Recommendations \\
\hline ACC/AHA stable angina guidelines 2002 [272] & Assess patients with previous PCI or CABG (1/Ba) \\
ASNC updated imaging guidelines [274] & Assess significance of known coronary lesion/plan PCI site (1/B) \\
& Evaluate revascularisation \\
Early assessment after PCI \\
ACC/AHA/ASNC guidelines for clinical use & Identify ischaemia/target site for PCI (1) \\
of radionuclide imaging 2003 [271] & Assess for restenosis after PCI (1) \\
& Assess symptomatic patients after CABG (1) \\
ACC/AHA stress testing guidelines 2002 & Selected asymptomatic patients after CABG (1) \\
& MPS “more desirable" than exercise ECG after CABG \\
BNCS/BNMS guidelines for SPET [277] & MPS better than exercise ECG after PCI but no specific recommendations \\
& Assessment of significance of coronary stenoses \\
& Assess adequacy of PCI and CABG procedures
\end{tabular}

CABG, Coronary artery bypass grafting; PCI, percutaneous coronary intervention; other abbreviations as defined in the list of abbreviations a Class of recommendation/level of evidence

cific subgroups [220]. Current BCS guidelines suggest that MPS is helpful after the exercise ECG if there is equivocal ST segment change, a negative test with a high pre-test likelihood of disease or a positive test with a low pre-test likelihood [276]. The BNMS/BNCS guidelines suggest that MPS is a useful procedure in most patients with suspected coronary artery disease [277].

\section{Women}

All of the guidelines recognise the reduced accuracy of the exercise ECG in women, but the degree to which MPS is recommended as an alternative first-line investigation, as opposed to a second-line investigation after the exercise ECG, is variable. The American guidelines suggest selective use [270, 272]. The American Society of Nuclear Cardiology states that MPS should be considered in all symptomatic women with an intermediate likelihood of CHD after an exercise ECG or as a first test if the resting ECG is abnormal, in diabetics or if poor exercise capacity is predicted [273]. British guidelines are conflicting. The National Service Framework proposes an exercise ECG for nearly all patients and, although it recognises problems with interpretation in women, it does not specifically advise on MPS unless exercise is not possible [220]. However, the BCS proposes MPS as a first-line test in all women with suspected CHD [276].

\section{Inability to exercise}

All guidelines propose MPS with pharmacological stress as a suitable test for the diagnosis of chest pain. Class 1 status is given by the American guidelines when there is intermediate pre-test likelihood of disease or previous coronary revascularisation [272]. In addition, vasodilator stress with
MPS is preferred to stress echocardiography in patients with left bundle branch block (LBBB) or paced rhythm. The BCS guidelines make pharmacological stress with MPS the first-line investigation for this indication [276] and the National Service Framework for Cardiovascular Disease (NSF) indicates that alternatives to the exercise ECG (such as "thallium scan") should be available [220].

\section{Abnormal resting ECG}

ST segment displacement with exercise is an unreliable indicator of ischaemia in patients with LBBB, ventricular pacing, resting ST segment depression greater than $1 \mathrm{~mm}$ or pre-excitation. Two of the American guidelines recommend MPS with pharmacological stress for patients with LBBB or ventricular pacing on ECG (class I indication) [270, 272] and MPS is recommended for patients with pre-excitation or resting ST segment change. The initial test may be coronary arteriography if clinical features suggest high risk. MPS is suggested for patients taking digoxin, although this is not common to all of the guidelines. In the UK, the NSF states that MPS is indicated in patients with a high likelihood of a false positive exercise ECG, and an abnormal resting ECG is probably included in this statement [220]. The BCS suggests that MPS should be the initial investigation in patients with resting ECG abnormalities [276].

\section{Assessment before or after revascularisation}

MPS is an accurate method for assessing the haemodynamic significance of known coronary lesions, identifying the site for potential revascularisation and assessing the result of previous coronary angioplasty or bypass surgery (Table 15). The exercise ECG performs poorly in 
Table 16. Recommendation for MPS in acute coronary syndromes

\begin{tabular}{|c|c|c|}
\hline Body & NSTEMI & STEMI \\
\hline ASNC updated imaging guidelines [274] & $\begin{array}{l}\text { Risk stratification post ACS } \\
\text { Exercise stress } \\
\text { Pharmacological stress if unable to exercise }\end{array}$ & $\begin{array}{l}\text { Risk stratification post MI } \\
\text { Exercise stress } \\
\text { Pharmacological stress if unable to exercise } \\
\text { Early risk stratification post MI-vasodilator } \\
\quad \text { stress }\end{array}$ \\
\hline $\begin{array}{l}\text { ACC/AHA/ASNC guidelines } \\
\text { for clinical use of radionuclide } \\
\text { imaging } 2003 \text { [271] }\end{array}$ & $\begin{array}{l}\text { Assess degree and site of ischaemia/ } \\
\text { culprit lesion }(1)^{\mathrm{a}} \\
\text { Risk stratification after medical } \\
\text { treatment }(2 \mathrm{a})\end{array}$ & $\begin{array}{l}\text { Demonstration of stress ischaemia } \\
\text { post MI (1) } \\
\text { Size of infarct or risk territory } \\
\text { (rest study) (2a) }\end{array}$ \\
\hline $\begin{array}{l}\text { ACC/AHA stress testing } \\
\text { guidelines } 2002 \text { [270] }\end{array}$ & Risk stratification in low-risk patients & $\begin{array}{l}\text { MPS after mildly abnormal standard } \\
\text { exercise ECG test } \\
\text { MPS first-line if abnormal ECG } \\
\text { or inability to exercise, in presence } \\
\text { of moderately low risk }\end{array}$ \\
\hline BNCS/BNMS guidelines for SPET [277] & & Determine prognosis after MI \\
\hline $\begin{array}{l}\text { European report on management } \\
\text { of NSTEMI [275] }\end{array}$ & $\begin{array}{l}\text { Pre-discharge testing suggested } \\
\text { for risk stratification } \\
\text { Pharmacological stress for poor } \\
\text { exercise capacity } \\
\text { MPS for low-risk patients with } \\
\text { inconclusive exercise ECG }\end{array}$ & \\
\hline $\begin{array}{l}\text { European report on STEMI } \\
\text { management [243] }\end{array}$ & & $\begin{array}{l}\text { Risk stratification for low-risk } \\
\text { and possibly intermediate-risk patients. } \\
\text { MPS defines extent of ischaemia } \\
\text { and is gatekeeper to invasive } \\
\text { management }\end{array}$ \\
\hline $\begin{array}{l}\text { BCS/RCP guideline for ACS } \\
\text { without ST segment } \\
\text { Elevation } 2001 \text { [278] }\end{array}$ & $\begin{array}{l}\text { Pharmacological MPS if unable } \\
\text { to exercise } \\
\text { Exercise ECG for others } \\
\text { Angiography for high-risk patients }\end{array}$ & \\
\hline
\end{tabular}

NSTEMI, Non-ST segment elevation myocardial infarction; STEMI, ST segment elevation myocardial infarction; ACS, acute coronary syndromes

these areas. Two of the American guidelines recommend MPS to identify the target lesion for coronary intervention and to assess symptomatic patients following bypass surgery (class 1 indications) [270, 272]. These indications are also mentioned in the joint BCS/BNCS/BNMS practice guidelines [277] but the area is not covered by the BCS guidelines on angina or by the NSF.

\section{Risk stratification after acute coronary syndromes}

Non-ST elevation myocardial infarction

European guidelines are that MPS should be performed for risk stratification after NSTEMI in patients who cannot exercise, in those with unhelpful exercise ECG tests and in women [275]. American guidelines also emph- a Numbers in parentheses refer to the class of recommendation

asise its use in low-risk medically stabilised patients. Recent UK guidelines recommend MPS in stabilised patients who cannot exercise [278]. Otherwise the standard exercise ECG is mainly suggested, although other stress tests are alluded to.

\section{ST elevation myocardial infarction}

American guidelines recommend MPS for risk stratification in low-risk patients following STEMI (Table 16). This is a class 1 indication [271] but the exercise testing guidelines [270] suggest that MPS should be used more selectively, in patients with mildly abnormal exercise ECGs or in those who have an uninterpretable ECG or who cannot exercise. The European guidelines suggest assessment of exercise tolerance and ischaemic burden 
Table 17. Recommendations for MPS for the assessment of ischaemic left ventricular dysfunction

\begin{tabular}{ll}
\hline Body & Recommendation \\
\hline $\begin{array}{l}\text { ACC/AHA/ASNC guidelines for clinical use } \\
\text { of radionuclide imaging 2003 [271] }\end{array}$ & Assess myocardial viability in LV impairment, ${ }^{201} \mathrm{Tl}$ suggested \\
BNCS/BNMS guidelines for SPET [277] & Assess myocardial viability and hibernation \\
European Report on STEMI management [243] & $\begin{array}{l}\text { MPS recommended to assess viability after angiography if LV impaired } \\
\text { Assess viability/ischaemia in most patients (imaging study preferred) }\end{array}$
\end{tabular}

and indicate that an imaging technique is superior to the exercise ECG [243].

\section{Assessment of ischaemic left ventricular dysfunction}

MPS is a key technique in the assessment of patients with ischaemic left ventricular dysfunction. Both European and American bodies recommend the technique after STEMI in patients with poor systolic function [243, 271] (Table 17). Thallium is specifically mentioned by the American guidelines for the assessment of myocardial viability, although gated imaging using technetium$99 \mathrm{~m}$ tracers can be particularly helpful. The joint BNCS/BNMS guidelines propose this as one of the four main indications for MPS [277].

\section{Service provision}

This section focusses mainly on service provision in the UK but the principles are relevant in other European countries.

\section{Current UK practice}

The foregoing demonstrates that the effectiveness and cost-effectiveness of MPS support its use for the diagnosis and management of patients with suspected and known CHD. Accordingly, the technique is an integral part of UK and other clinical guidelines and it has long been used routinely in many centres. However, there is a general perception among those familiar with the field that the technique is not used to its full potential and that service provision in the UK has three main problems:

1. MPS is either not available or not requested in patients where the evidence and guidelines suggest benefit. An example might be the lack of nuclear cardiology support for many rapid access chest pain clinics [266, 267].

2. MPS is available but the waiting time is too long for the test to be clinically useful.

3. MPS provision is not of a uniform high standard in all centres.

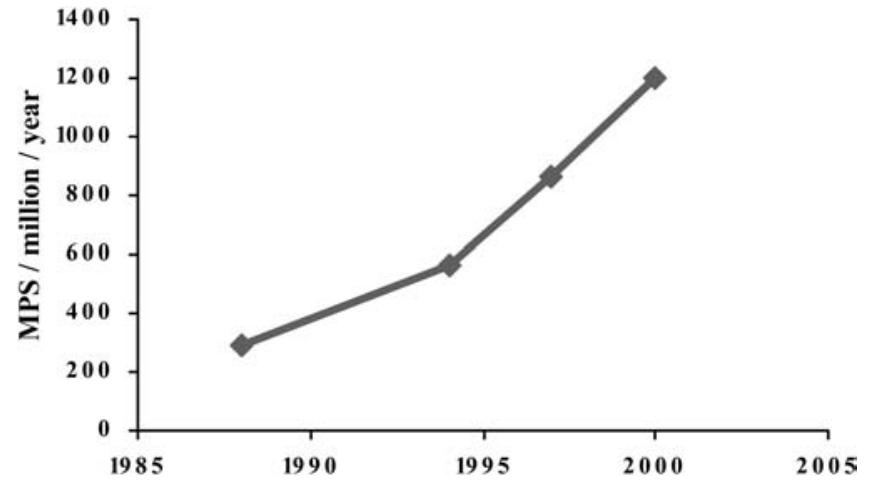

Fig. 8. Growth of MPS in the UK from BNCS surveys

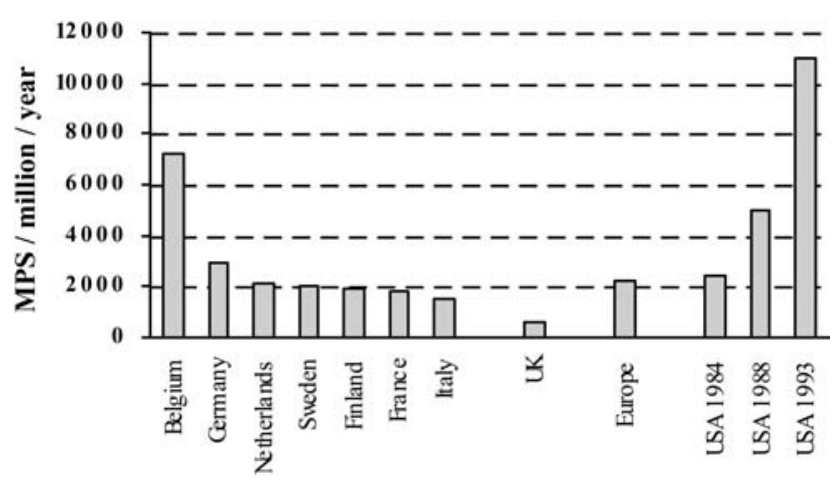

Fig. 9. Numbers of MPS studies in selected countries in 1994 (except where stated). (Adapted from references [280] and [290])

\section{MPS activity in the UK}

Since 1988 the BNCS has conducted regular surveys of nuclear cardiology practice. The 1988 [279], 1994 [280] and 1997 [281] surveys are published and data from the 2000 survey are available on request. The number of MPS studies performed per million population per year (pm) has increased over this period at a linear annual rate of $26 \%$ or at a compound rate of $12.5 \%$ (Fig. 8). Nevertheless, the figure for 2000 was still only 1,200 pm, with a median number of studies per centre of 256 per year.

Comparative data from 1994 show that the UK figure at this time, $560 \mathrm{pm}$, was significantly below the European average of 2,200 pm and very small compared with a comparable US figure of 10,000 pm (Fig. 9) [280]. 


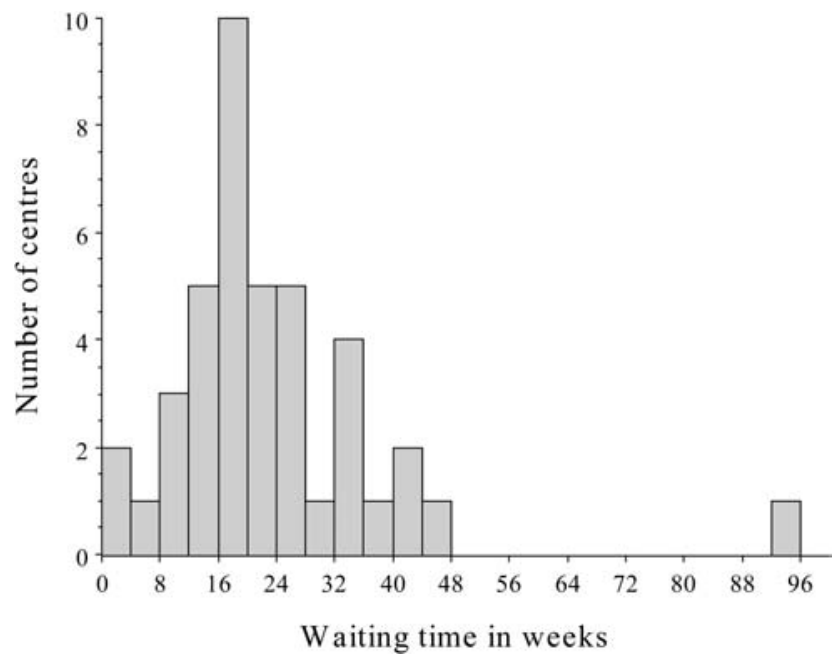

Fig. 10. Histogram of waiting times for MPS from the BNCS 2000 UK survey

Table 18. Target and actual waiting times for MPS at Royal Brompton Hospital, London

\begin{tabular}{lll}
\hline Clinical urgency & Target waiting time & Actual waiting time \\
\hline Routine & 6 weeks & 20 weeks \\
Soon & 3 weeks & 12 weeks \\
Urgent & 1 week & 2 weeks \\
Immediate & 1 day & 2 days \\
\hline
\end{tabular}

Actual waiting times

The BNCS 2000 survey found a mean waiting time of 20 weeks, with the low-volume centres having a somewhat longer mean waiting time (27 weeks) than the high-volume centres (17 weeks) (Fig. 10). Many centres prioritise referrals according to clinical urgency and, for example, at the largest UK centre, with 5,500 patients per year, the actual waiting times are shown in Table 18. Target waiting times are almost achieved for urgent patients but at the expense of the less urgent.

Nature and quality of MPS in the UK

The BNCS 2000 survey showed a move from dynamic exercise to pharmacological stress, which is used in $77 \%$ of all studies, and a move from thallium-201 to the technetium-99m based tracers, which are now used in 59\% of all studies. Eight-eight percent of studies used emission tomography imaging, 22\% used ECG-gated acquisition, and $38 \%$ were supervised or reported by a cardiologist.

Another factor influencing use of MPS is the quality of studies. With modern equipment and published proto- cols it is relatively straightforward to perform the technical aspects of the study, but experience is required when reporting. A BNCS/BNMS audit of quality assurance in MPS demonstrated that $81 \%$ of studies in the random sample were technically of good or adequate quality, but only $68 \%$ of reports were good or adequate. [282]. Most of the reports considered inadequate were so assessed because they over-reported artefact or were clinically irrelevant or misleading. Since this time the BNCS and BNMS have concentrated their educational efforts on reporting skills through a combination of dedicated training meetings, symposia and training materials [283]. Although the audit has not yet been repeated, the impression within the profession is that quality is improving.

The low utilisation of MPS in the UK most likely arises from a combination of low perceived demand and inadequate supply. In all but a handful of centres, MPS is performed in general nuclear medicine departments, outside the direct experience of referring cardiologists and in marked contrast to other cardiac investigations such as echocardiography and angiography. It is unsurprising that the test may not be requested even when it can be clinically helpful, or that it is not available sufficiently rapidly to assist with clinical management. This vicious circle has been broken in a small number of high-volume centres where clinically relevant studies of high quality are provided. Growth in MPS is concentrated in these high-volume centres, but the clinical effectiveness and cost-effectiveness of MPS remain largely academic in many hospitals that do not have access to a reliable nuclear cardiology service.

\section{Estimate of need}

If there is a perception of underutilisation of MPS in the UK, how should correct usage be judged? Comparisons with practice in other countries cannot adequately answer this question but the UK is at the lower end of the spectrum for both absolute and relative numbers of studies and it therefore behoves those concerned to justify this position as an outlier.

\section{Past recommendations}

The BCS considered levels of provision of a number of investigations in 1994 (Fig. 11) [284, 285]. In all cases the recommended target was lower than the actual number of studies but for MPS the discrepancy was greatest, with a recommendation of 2,200 pm compared with actual numbers of $560 \mathrm{pm}$. At this time the recommendation for revascularisations (percutaneous and surgical) was $1,000 \mathrm{pm}$ and, based upon this, the recommendation for coronary angiography was $2,000 \mathrm{pm}$. The ratio of $2: 1$ was based upon the fact that angiography does not always proceed to revascularisation and a single interven- 


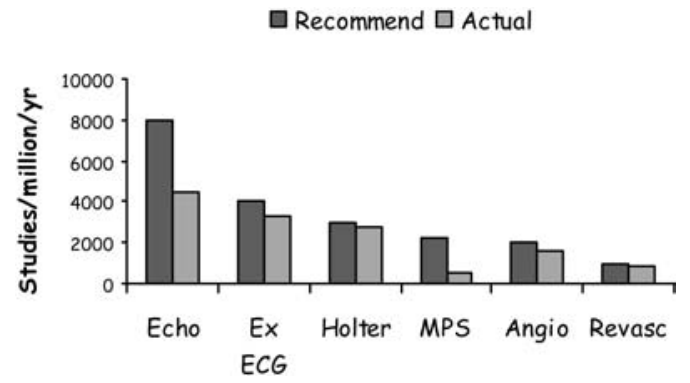

Fig. 11. BCS recommended and actual numbers of procedures in 1994, adapted from reference [284]. Echo, Echocardiography; Ex ECG, exercise electrocardiography; Holter, 24-h ECG; Angio, coronary angiography; Revasc, myocardial revascularisation

tion may be associated with more than a single angiogram. The concept was that angiography acts as the "gatekeeper" to revascularisation.

\section{Estimation of need}

The same concept can be used to estimate numbers of MPS studies compared with angiograms. If intervention in patients with CHD is normally performed either to relieve symptoms or to improve prognosis and if objective evidence of inducible ischaemia is required before intervention, then angiography should normally be preceded by MPS, at least in stable coronary disease. The same ratio of 2:1 for MPS to angiography might therefore be a reasonable estimate.

The UK Department of Health has set a target of 1,500 revascularisations per million per year [220], and this is credibly related to population need although with upper estimates of need being considerably higher [286]. In the UK in 2001, 2,600 non-interventional coronary angiograms were performed per million, compared with an estimated number of revascularisations of 1,161 per million (684 pm PCIs + 477 pm CABG) [287]. Thus the ratio of MPS to angiography to revascularisation is $1,200: 2,600: 1,161$, contrasting sharply with corresponding numbers in the USA in 1996 of 12,800:7,200:5,050 (Fig. 12) [288]. The most important contrast is not the difference in scale but the difference in ratios. If it is assumed that an optimal ratio of MPS to angiography to revascularisation is in the region of $4: 2: 1$, this implies a target number of MPS studies of 6,000 pm compared with the target number of revascularisations, or $5,200 \mathrm{pm}$ compared with the actual number of angiograms.

This analysis clearly makes a number of assumptions, not least the presumed optimal ratios, and it is therefore important to err on the side of caution. However, a target for MPI studies of 4,000 pm is reasonable and it would be consistent with practice in other large European countries.

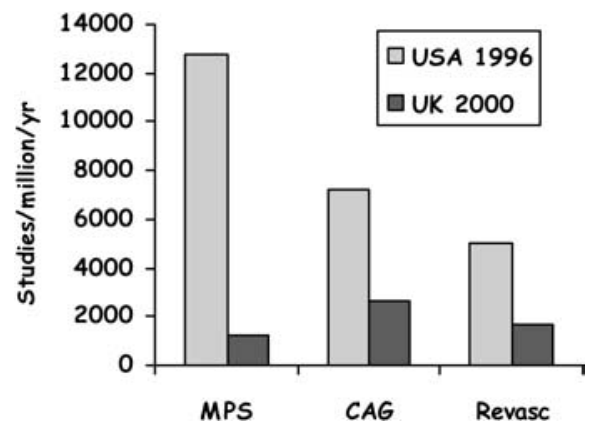

Fig. 12. Numbers of procedures performed in USA in 1996 and UK in 2000. CAG, Coronary angiography; Revasc, myocardial revascularisation

Table 19. Second-phase NSF targets for waiting times [220]

GP referral to cardiologist

2 weeks

or rapid access chest pain clinic

Specialist investigation

General

Rapid access chest pain clinic

"Prompt"

2 weeks

Decision to investigate to angiography 3 months

Decision to operate to PCI

3 months

Decision to operate to surgery

High risk

3 months

Others

6 months

PCI, Percutaneous coronary intervention

Clinically appropriate waiting time

Table 19 shows selected second-phase waiting times targets from the NSF. These have not been achieved in all centres but waiting time initiatives have successfully reduced the waiting times to intervention. No targets were proposed for MPS except indirectly by requiring completion of diagnosis and assessment in rapid access chest pain clinics within 2 weeks. Clearly an actual waiting time for MPS of 20 weeks is inconsistent with these targets. Waiting time targets have been recommended in the South East Thames region at 2 weeks for routine studies and within 2 days for urgent studies [289]. This covers the full range of nuclear medicine procedures, including diagnostic and staging studies for malignancy. Against this background, we propose that suitable waiting time targets for MPS would be 6 weeks for routine studies and 1 week for urgent studies. 
Acknowledgements. The following people either took part in the consensus conference or commented on the manuscript: Dr. Andries van Aswegen, Dr. John Barker, Dr. Jamshed Bomanji, Dr. John Buscombe, Professor Martin Buxton, Professor Paolo Camici, Professor John Camm, Professor John Cleland, Dr. Norman Campbell, Dr. Neil Garvie, Dr. Paul Hinton, Professor Peter Jarritt, Dr. Avijit Lahiri, Dr. Jim McKillop, Professor Michael Maisey, Dr. William Martin, Dr. Vahini Naidoo, Dr. Tom Nunan, Ms Vicki Parkin, Professor Dudley Pennell, Dr. Mary Prescott, Dr. Philip Thomas, Dr. Wendy Tindale and Dr. Gill Vivian. We thank the American Society of Nuclear Cardiology for its assistance, Ann Moulson of Serac Communications for assistance with writing and Sonia Crossley for administrative assistance. We also thank Amersham Health, Bristol Myers Squibb, GE Medical Systems and Philips Medical Systems for financial support for the meeting but they took no part in planning, drafting, writing or approving this document.

\section{References}

1. Rochmis P, Blackburn H. Exercise tests. A survey of procedures, safety and litigation experience in approximately 170,000 tests. JAMA 1971; 217:1061-1066.

2. Cerqueira MD, Verani MS, Schwaiger M, et al. Safety profile of adenosine stress perfusion imaging: results from the Adenoscan multicenter trial registry. J Am Coll Cardiol 1994; 23:3849.

3. Lette J, Tatum JL, Fraser S, et al. Safety of dipyridamole testing in 73,806 patients: the multicentre dipyridamole safety study. J Nucl Cardiol 1995; 2:3-17.

4. Mertes H, Sawada SG, Ryan T, et al. Symptoms, adverse effects, and complications associated with dobutamine stress echocardiography: experience in 1118 patients. Circulation 1993; 88:15-19.

5. Administration of Radioactive Substances Advisory Committee. Notes for guidance on the clinical administration of radiopharmaceuticals and use of sealed radioactive sources. Didcot, UK: ARSAC Support Unit, National Radiological Protection Board, 1998.

6. Coulden RA, Readman LP. Coronary angiography - an analysis of radiographic practice in the UK. Br J Radiol 1993; 784:327-331.

7. Mountford PJ. Risk assessment of the nuclear medicine patient. Br J Radiol 1997; 70:671-684.

8. Lozner EC, Johnson LW, Johnson S, et al. Coronary arteriography 1984-1987: a report of the registry of the Society for Cardiac Angiography and Interventions II: an analysis of 218 deaths related to coronary angiography. Cathet Cardiovasc Diag 1989; 17:11-14.

9. Irwig L, Tosteson ANA, Gatsonis C, et al. Guidelines for meta-analyses evaluating diagnostic tests. Ann Intern Med 1994; 120:667-676.

10. Bossuyt PM, Reitsma JB, Bruns DE, et al. Towards complete and accurate reporting of studies of diagnostic accuracy: the STARD initiative. Br Med J 2003; 326:41-44.

11. Tamaki N, Yonekura Y, Mukai T, et al. Stress thallium-201 transaxial emission computed tomography: quantitative versus qualitative analysis for evaluation of coronary artery disease. J Am Coll Cardiol 1984; 4:1213-1221.

12. DePasquale EE, Nody AC, DePuey EG, et al. Quantitative rotational thallium-201 tomography for identifying and localising coronary artery disease. Circulation 1988; 2:316-327.
13. Fintel DJ, Links JM, Brinker JA, et al. Improved diagnostic performance of exercise thallium-201 single photon emission computed tomography over planar imaging in the diagnosis of coronary artery disease: a receiver operating characteristic analysis. J Am Coll Cardiol 1989; 13:600-612.

14. Iskandrian AS, Heo J, Kong B, Lyons E. Effect of exercise level on the ability of thallium-201 tomographic imaging in detecting coronary artery disease: analysis of 461 patients. J Am Coll Cardiol 1989; 14:1477-1486.

15. Maddahi J, Van Train K, Pringent F, et al. Quantitative single photon emission computed thallium-201 tomography for detection and localization of coronary artery disease: optimization and prospective validation of a new technique. J Am Coll Cardiol 1989; 14:1689-1699.

16. Mahmarian JJ, Boyce TM, Goldberg RK, et al. Quantitative exercise thallium-201 single photon emission computed tomography for the enhanced diagnosis of ischaemic heart disease. J Am Coll Cardiol 1990; 15:318-329.

17. Van Train KF, Maddahi J, Berman DS, et al. Quantitative analysis of tomographic stress thallium-201 myocardial scintigrams: a multicenter trial. J Nucl Med 1990; 31:1168-1179.

18. Coyne EP, Belvedere DA, Vande Streek PR, et al. Thallium201 scintigraphy after intravenous infusion of adenosine compared with exercise thallium testing in the diagnosis of coronary artery disease. J Am Coll Cardiol 1991; 17:1289-1294.

19. Quinones MA, Verani MS, Haichin RM, et al. Exercise echocardiography versus Tl-201 single-photon emission computed tomography in evaluation of coronary artery disease. Circulation 1992; 85:1026-1031.

20. Chae SC, Heo J, Iskandrian AS, Wasserleben V, Cave V. Identification of extensive coronary artery disease in women by exercise single-photon emission computed tomographic (SPECT) thallium imaging. J Am Coll Cardiol 1993; 21:1305-1311.

21. Grover-McKay M, Milne N, Atwood E, Lyons KP. Comparison of thallium-201 single-photon emission computed tomographic scintigraphy with intravenous dipyridamole and arm exercise. Am Heart J 1994; 127:1516-1520.

22. Tamaki N, Takahashi N, Kawamoto M, et al. Myocardial tomography using technetium-99m tetrofosmin to evaluate coronary artery disease. J Nucl Med 1994; 35:594-600.

23. Ho Y-L, Wu C-C, Huang P-J, et al. Dobutamine stress echocardiography compared with exercise thallium-201 singlephoton emission computed tomography in detecting coronary artery disease-effect of exercise level on accuracy. Cardiology 1997; 88:379-385.

24. Kiat H, Van Train KF, Maddahi J, et al. Development and prospective application of quantitative 2-day stress-rest Tc-99m methoxy isobutyl isonitrile SPECT for the diagnosis of coronary artery disease. Am Heart J 1990; 120:1255-1266.

25. Pozzoli MMA, Fioretti P, Salustri A, et al. Exercise echocardiography and technetium-99m MIBI single-photon emission computed tomography in the detection of coronary artery disease. Am J Cardiol 1991; 67:350-355.

26. Solot G, Hermans J, Merlo P, et al. Correlation of Tc-99m sestamibi SPECT with coronary angiography in general hospital practice. Nucl Med Commun 1993; 14:23-29.

27. Marwick TH, D'Hondt AM, Mairesse GH, et al. Comparative ability of dobutamine and exercise stress in inducing myocardial ischaemia in active patients. Br Heart J 1994; 72:31-38.

28. Van Train KF, Garcia EV, Maddahi J, et al. Multicenter trial validation for quantitative analysis of same-day rest-stress technetium-99m-sestamibi myocardial tomograms. J Nucl Med 1994; 35:609-618. 
29. Heo J, Cave V, Wasserleben V, Iskandrian AS. Planar and tomographic imaging with technetium-99m-labeled tetrofosmin: correlation with thallium-201 and coronary angiography. J Nucl Cardiol 1994; 1:317-324.

30. Benoit T, Vivegnis D, Lahiri A, et al. Tomographic myocardial imaging with technetium-99m tetrofosmin. Eur Heart J 1996; 17:635-642.

31. Shanoudy H, Raggi P, Beller GA, et al. Comparison of technetium-99m tetrofosmin and thallium-201 single-photon emission computed tomographic imaging for detection of myocardial perfusion defects in patients with coronary artery disease. J Am Coll Cardiol 1998; 31:331-337.

32. Francisco DA, Collins SM, Go RT, et al. Tomographic thaalium-201 myocardial perfusion scintigrams after maximal coronary artery vasodilation with intravenous dipyridamole. Circulation 1982; 66:370-379.

33. Huikuri HV, Korhonen UR, Airaksinen KEJ, et al. Comparison of dipyridamole-handgrip test and bicycle exercise test for thallium tomographic imaging. Am J Cardiol 1988; 61:264268.

34. Go RT, Marwick TH, MacIntyre WJ, et al. A prospective comparison of rubidium-82 PET and thallium-201 SPECT myocardial perfusion imaging utilizing a single dipyridamole stress in the diagnosis of coronary artery disease. $\mathrm{J} \mathrm{Nucl} \mathrm{Med}$ 1990; 31:1899-1905.

35. Mendelson MA, Spies SM, Spies WG, et al. Usefulness of single- photon emission computed tomography of thallium-201 uptake after dipyridamole infusion for detection of coronary artery disease. Am J Cardiol 1992; 69:1150-1155.

36. Cramer M-J, Verzijlbergen JF, Van der Wall EE, et al. Headto-head comparison between technetium-99m-sestamibi and thallium-201 tomographic imaging for the detection of coronary artery disease using combined dipyridamole-exercise stress. Coron Artery Dis 1994; 5:787-791.

37. Ho F-M, Huang P-J, Liau C-S, et al. Dobutamine stress echocardiography compared with dipyridamole thallium-201 singlephoton emission computed tomography in detecting coronary artery disease. Eur Heart J 1995; 16:570-575.

38. Watanabe K, Sekiya M, Ikeda S, et al. Comparison of adenosine triphosphate and dipyridamole in diagnosis by thallium201 myocardial scintigraphy. J Nucl Med 1997; 38:577-581.

39. Tartagni F, Dondi M, Limonetti P, et al. Dipyridamole technetium-99m 2-methoxy isobutyl isonitrile tomoscintigraphic imaging for identifying diseased coronary vessels: comparison with thallium-201 stress-rest study. J Nucl Med 1991; 32: 369-376.

40. Miller DD, Younis LT, Chaitman BR, Stratmann H. Diagnostic accuracy of dipyridamole technetium-99m-labeled sestamibi myocardial tomography for detection of coronary artery disease. J Nucl Cardiol 1997; 4:18-24.

41. Schillaci O, Moroni C, Scopinaro F, et al. Technetium-99m sestamibi myocardial tomography based on dipyridamole echocardiography testing in hypertensive patients with chest pain. Eur J Nucl Med 1997; 24:774-778.

42. Soman P, Khattar R, Senior R, Lahiri A. Inotropic stress with arbutamine is superior to vasodilator stress with dipyridamole for the detection of reversible ischaemia with Tc-99m sestamibi single-photon emission computed tomography. J Nucl Cardiol 1997; 4:364-371.

43. Ogilby JD, Kegel JG, Heo J, Iskandrian AE. Correlation between haemodynamic changes and tomographic sestamibi imaging during dipyridamole-induced coronary hyperaemia. J Am Coll Cardiol 1998; 31:75-82.
44. Santoro GM, Sciagra R, Buonamici P, et al. Head-to-head comparison of exercise stress testing, pharmacologic stress echocardiography and perfusion tomography as first-line examination for chest pain in patients without history of coronary artery disease. J Nucl Cardiol 1998; 5:19-27.

45. He Z-X, Iskandrian AS, Gupta NC, Verani MS. Assessing coronary artery disease with dipyridamole technetium-99m tetrofosmin SPECT: a multicenter trial. J Nucl Med 1997; 38:44-48.

46. Nguyen T, Heo J, Ogilby JD, Iskandrian AS. Single photon emission computed tomography with thallium-201 during adenosine-induced coronary hyperaemia: correlation with coronary arteriography, exercise thallium imaging and two-dimensional echocardiography. J Am Coll Cardiol 1990; 16: 1375-1383.

47. Verani MS, Mahmarian JJ, Hixson JB, et al. Diagnosis of coronary artery disease by controlled coronary vasodilation with adenosine and thallium-201 scintigraphy in patients unable to exercise. Circulation 1990; 82:80-87.

48. Nishimura S, Mahmarian JJ, Boyce TM, Verani MS. Quantitative thallium-201 single-photon emission computed tomography during maximal pharmacologic coronary vasodilation with adenosine for assessing coronary artery disease. $J \mathrm{Am}$ Coll Cardiol 1991; 18:736-745.

49. Allman KC, Berry J, Sucharski LA, et al. Determination of extent and location of coronary artery disease in patients without prior myocardial infarction by thallium-201 tomography with pharmacologic stress. J Nucl Med 1992; 33:2067-2073.

50. Pennell DJ, Mavrogeni SI, Forbat SM, et al. Adenosine combined with dynamic exercise for myocardial perfusion imaging. J Am Coll Cardiol 1995; 25:1300-1309.

51. Mohiuddin SM, Ravage CK, Esterbrooks DJ, et al. The comparative safety and diagnostic accuracy of adenosine myocardial perfusion imaging in women versus men. Pharmacotherapy 1996; 16:646-651.

52. Amanullah AM, Bevegard S, Lindvall K, Aasa M. Assessment of left ventricular wall motion in angina pectoris by two -dimensional echocardiography and myocardial perfusion by technetium-99m sestamibi tomography during adenosineinduced coronary vasodilation and comparison with coronary angiography. Am J Cardiol 1993; 72:983-989.

53. Marwick T, Willemart B, D'Hondt A-M, et al. Selection of the optimal nonexercise stress for the evaluation of ischaemic regional myocardial dysfunction and malperfusion. Circulation 1993; 87:345-354.

54. Jamil G, Ahlberg AW, Elliott MD, et al. Impact of limited treadmill exercise on adenosine Tc-99m sestamibi singlephoton emission computed tomographic myocardial perfusion imaging in coronary artery disease. Am J Cardiol 1999; 84: 400-403.

55. Kapur A, Latus KA, Davies G, et al. A comparison of three radionuclide myocardial perfusion tracers in clinical practice: the ROBUST study. Eur J Nucl Med Mol Imaging 2002; 29:1608-1616.

56. Pennell DJ, Underwood SR, Swanton RH, et al. Dobutamine thallium myocardial perfusion tomography. J Am Coll Cardiol 1991; 18:1471-1479.

57. Warner MF, Pippin JJ, DiSciascio G, et al. Assessment of thallium scintigraphy and echocardiography during dobutamine infusion for the detection of coronary artery disease. Cathet Cardiovasc Diagn 1993; 29:122-127.

58. Hays JT, Mahmarian JJ, Cochran AJ, Verani MS. Dobutamine thallium-201 tomography for evaluating patients with suspected coronary artery disease unable to undergo exercise or vaso- 
dilator pharmacologic stress testing. J Am Coll Cardiol 1993; 21:1583-1590.

59. Huang P-J, Ho Y-L, Wu C-C, et al. Simultaneous dobutamine stress echocardiography and thallium-201 perfusion imaging for the detection of coronary artery disease. Cardiology 1997; 88:556-562.

60. Huang P-J, Yen R-F, Chieng P-U, et al. Do $\beta$-blockers affect the diagnostic sensitivity of dobutamine stress thallium-201 single photon emission computed tomographic imaging? J Nucl Cardiol 1998; 5:34-39.

61. Caner B, Karanfil A, Uysal U, et al. Effect of an additional atropine injection during dobutamine infusion for myocardial SPET. Nucl Med Commun 1997; 18:567-573.

62. Gunalp B, Dokumaci B, Uyan C, et al. Value of dobutamine technetium-99m-sestamibi SPECT and echocardiography in the detection of coronary artery disease compared with coronary angiography. J Nucl Med 1993; 34:889-894.

63. Forster T, McNeill AJ, Salustri A, et al. Simultaneous dobutamine stress echocardiography and technetium- $99 \mathrm{~m}$ isonitrile single-photon emission computed tomography in patients with suspected coronary artery disease. J Am Coll Cardiol 1993; 21:1591-1596.

64. Marwick T, D'Hondt A-M, Baudhuin T, et al. Optimal use of dobutamine stress for the detection and evaluation of coronary artery disease: combination with echocardiography or scintigraphy, or both? J Am Coll Cardiol 1993; 22:159-167.

65. Mairesse GH, Marwick TH, Vanoverschelde J-L, et al. How accurate is dobutamine stress electrocardiography for detection of coronary artery disease? Comparison with two-dimensional echocardiography and technetium-99m methoxy isobutyl isonitrile perfusion scintigraphy. J Am Coll Cardiol 1994; 24:920-927.

66. Senior R, Sridhara BS, Anagnostou E, et al. Synergistic value of simultaneous stress dobutamine sestamibi single-photon emission computerized tomography and echocardiography in the detection of coronary artery disease. Am Heart J 1994; 128:713-718.

67. Di Bello V, Bellina CR, Gori E, et al. Incremental diagnostic value of dobutamine stress echocardiography and dobutamine scintigraphy (technetium-99m-labeled sestamibi single-photon emission computed tomography) for assessment of presence and extent of coronary artery disease. J Nucl Cardiol 1996; 3:212-220.

68. Iftihar I, Koutelou M, Mahmarian JJ, Verani MS. Simultaneous perfusion tomography and radionuclide angiography during dobutamine stress. J Nucl Med 1996; 37:1306-1310.

69. Kisacik HL, Ozdemir K, Altinyay E, et al. Comparison of exercise stress testing with simultaneous dobutamine stress echocardiography and technetium-99m isonitrile single-photon emission computerized tomography for diagnosis of coronary artery disease. Eur Heart J 1996; 17:113-119.

70. Slavich GA, Guerra UP, Morocutti G, et al. Feasibility of simultaneous Tc-99m sestamibi and 2D-echo cardiac imaging during dobutamine pharmacologic stress: preliminary results in a female population. Int J Card Imaging 1996; 12:113-118.

71. San Roman JA, Vilacosta I, Castillo JA, et al. Selection of the optimal stress test for the diagnosis of coronary artery disease. Heart 1998; 80:370-376.

72. Elhendy A, von Domburg RT, Bax JJ, et al. Non-invasive diagnosis of coronary artery stenosis in women with limited exercise capacity: comparison of dobutamine stress echocardiography and Tc-99m sestamibi single-photon emission CT. Chest 1998; 114:1097-1104.
73. Taillefer R, DePuey G, Udelson JE, et al. Comparative diagnostic accuracy of Tl-201 and Tc-99m sestamibi SPECT imaging (perfusion and ECG-gated SPECT) in detecting coronary artery disease in women. J Am Coll Cardiol 1997; 29:69-77.

74. Berman DS, Hayes SW, Shaw LJ, German G. Recent advances in myocardial perfusion imaging. Curr Prob Cardiol 2001; 26:54-59.

75. Rozanski A. Referral bias and the efficacy of radionuclide stress tests: problems and solutions. J Nucl Med 1992; 33: 2074-2079.

76. Maddahi J, Rodrigues E, Berman DS, Kiat H. State-of-the-art myocardial perfusion imaging. Cardiol Clin North Am 1994; 12:199-222.

77. Rozanski A, Diamond G, Berman DS, et al. The declining specificity of exercise radionuclide ventriculography. $N$ Engl $J$ Med 1983; 309:518-522.

78. Roger VL, Pellikka PA, Bell MR, et al. Sex and test verification bias: impact on the diagnostic value of exercise echocardiography. Circulation 1997; 95:405-410.

79. Begg CB, Greenes RA. Assessment of diagnostic tests when disease verification is subject to selection bias. Biometrics 1983; 39:207-215.

80. Diamond GA. Reverend Bayes' silent majority: an alternative factor affecting sensitivity and specificity of exercise electrocardiography. Am J Cardiol 1986; 5:1175-1180.

81. Miller TD, Hodge DO, Christian TF, et al. Effects of adjustment for referral bias on the sensitivity and specificity of single photon emission computed tomography for the diagnosis of coronary artery disease. Am J Med 2002; 112:290-297.

82. Kiat H, Van Train KF, Friedman JD, et al. Quantitative stressredistribution thallium-201 SPECT using prone imaging: methodologic development and validation. J Nucl Med 1992; 33:1509-1515.

83. Detrano R, Janosi A, Lyons KP, et al. Factors affecting sensitivity and specificity of a diagnostic test: the exercise thallium scintigram. Am J Med 1988; 84:699-710.

84. Heller GV, Ahmed I, Tilkemeier PL, et al. Comparison of chest pain, electrocardiographic changes and thallium-201 scintigraphy during varying exercise intensities in men with stable angina pectoris. Am J Cardiol 1991; 68:569-574.

85. Hockings B, Saltissi S, Croft DN, Webb-Peploe MM. Effect of beta adrenergic blockade on thallium-201 myocardial perfusion imaging. Br Heart J 1983; 49:83-89.

86. Martin GJ, Henkin RE, Scalon PJ. Beta blockers and the sensitivity of the thallium treadmill test. Chest 1987; 92:486-487.

87. Strauss HW, Miller DD, Wittry MD, et al. Society of Nuclear Medicine procedure guideline for myocardial perfusion imaging. J Nucl Med 1998; 39:918-923.

88. Sharir T, Rabinowitz B, Livschitz S, et al. Underestimation of extent and severity of coronary artery disease by dipyridamole stress thallium-201 single-photon emission computed tomographic myocardial perfusion imaging in patients taking antianginal drugs. J Am Coll Cardiol 1998; 31:1540-1546.

89. Ficaro EP, Fessler JA, Shreve PD, et al. Simultaneous transmission/emission myocardial perfusion tomography: diagnostic accuracy of attenuation-corrected Tc-99m sestamibi singlephoton emission computed tomography. Circulation 1996; 93: 463-473.

90. Vidal R, Buvat I, Darcourt J, et al. Impact of attenuation correction by simultaneous emission/transmission tomography on visual assessment of thallium-201 myocardial perfusion images. J Nucl Med 1999; 40:1301-1309. 
91. Hendel RC. Berman DS, Cullom SJ, et al. Multicenter clinical trial to evaluate the efficacy of correction for photon attenuation and scatter in SPECT myocardial perfusion imaging. Circulation 1999; 99:2742-2749.

92. Links JM, Becker LC, Rigo P, et al. Combined corrections for attenuation, depth-dependent blur and motion in cardiac SPECT: a multicenter trial. J Nucl Cardiol 2000; 7:414-425.

93. Shotwell M, Singh BM, Fontman C, et al. Improved coronary disease detection with quantitative attenuation-corrected Tl-201 images. J Nucl Cardiol 2002; 9:52-61.

94. DePuey EG, Rozanski A. Using gated technetium-99m sestamibi SPECT to characterize fixed myocardial defects as infarct or artifact. J Nucl Med 1995; 36:952-955.

95. Smanio PE, Watson DD, Segalla DL, et al. Value of gating of technetium-99m sestamibi single-photon emission computed tomographic imaging. J Am Coll Cardiol 1997; 30:1687-1692.

96. Choi JY, Lee KH, Kim SJ, et al. Gating provides improved accuracy for differentiating artifacts from true lesions in equivocal fixed defects on technetium-99m tetrofosmin perfusion SPECT. J Nucl Cardiol 1998; 5:395-401.

97. Sharir T, Germano G, Kavanagh PB, et al. Incremental prognostic value of post-stress left ventricular ejection fraction and volume by gated myocardial perfusion single photon emission computed tomography. Circulation 1999; 100:1035-1042.

98. Glover DK, Ruiz M, Yang JY, et al. Myocardial Tc-99m tetrofosmin uptake during adenosine-induced vasodilatation with either a critical or mild coronary stenosis: comparison with Tl-201 and regional myocardial blood flow. Circulation 1997; 96:2332-2338.

99. Soman O, Taillefer R, DePuey EG, et al. Enhanced detection of reversible perfusion defects by Tc-99m sestamibi compared to Tc-99m tetrofosmin during vasodilator stress SPECT imaging in mild-to-moderate coronary artery disease. $\mathrm{J} \mathrm{Am}$ Coll Cardiol 2001; 37:458-462.

100. Brown KA. Prognostic value of thallium-201 myocardial perfusion imaging. A diagnostic tool comes of age. Circulation 1991; 83:363-381.

101. Brown KA. Prognostic value of cardiac imaging in patients with known or suspected coronary artery disease: comparison of myocardial perfusion imaging, stress echocardiography, and positron emission tomography. Am J Cardiol 1995; 75:D35-D41.

102. Brown KA. Prognostic value of myocardial perfusion imaging: state of the art and new developments. J Nucl Cardiol 1996; 3:516-537.

103. Ladenheim ML, Pollock BH, Rozanski A, et al. Extent and severity of myocardial hypoperfusion as predictors of prognosis in patients with suspected coronary artery disease. $J$ Am Coll Cardiol 1986; 7:464-471.

104. Gill JB, Ruddy TD, Newell JB, Finkelstein DM, Strauss HW, Boucher CA. Prognostic importance of thallium uptake by the lungs during exercise in coronary artery disease. $N$ Engl $J$ Med 1987; 317:1486-1489.

105. Weiss AT, Berman DS, Lew AS, et al. Transient ischemic dilation of the left ventricle on stress thallium-201 scintigraphy: a marker of severe and extensive coronary artery disease. J Am Coll Cardiol 1987; 9:752-759.

106. Gioia G, Milan E, Giubbini R, DePace N, Heo J, Iskandrian AS. Prognostic value of tomographic rest-redistribution thallium 201 imaging in medically treated patients with coronary artery disease and left ventricular dysfunction. J Nucl Cardiol 1996; 3:150-156.
107. Johnson LL, Verdesca SA, Aude WY, et al. Postischemic stunning can affect left ventricular ejection fraction and regional wall motion on post-stress gated sestamibi tomograms. J Am Coll Cardiol 1997; 30:1641-1648.

108. Hachamovitch R, Berman DS, Shaw LJ, et al. Incremental prognostic value of myocardial perfusion single photon emission computed tomography for the prediction of cardiac death: differential stratification for risk of cardiac death and myocardial infarction. Circulation 1998; 97:535-543.

109. Sharir T, Germano G, Kang X, et al. Prediction of myocardial infarction versus cardiac death by gated myocardial perfusion SPECT: risk stratification by the amount of stress-induced ischemia and the poststress ejection fraction. J Nucl Med 2001; 42:831-847.

110. Iskandrian AS, Chae SC, Heo J, Stanberry CD, Wasserleben V, Cave V. Independent and incremental prognostic value of exercise single-photon emission computed tomographic (SPECT) thallium imaging in coronary artery disease. J Am Coll Cardiol 1993; 22:665-670.

111. Klocke F, et al. ACC/AHA/ASNC guidelines for the clinical use of cardiac radionuclide imaging 2003. Personal communication.

112. Shaw LJ, Hendel R, Borges-Neto S, et al. Prognostic value of

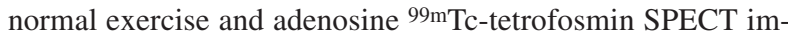
aging: results from the multicenter registry of 4,728 patients. J Nucl Med 2003; 44:134-139.

113. Galassi AR, Azzarelli S, Tomaselli A, et al. Incremental prognostic value of technetium-99m-tetrofosmin exercise myocardial perfusion imaging for predicting outcomes in patients with suspected or known coronary artery disease. Am J Cardiol 2001; 88:101-106.

114. Vanzetto G, Ormezzano O, Fagret D, Comet M, Denis B, Machecourt J. Long-term additive prognostic value of thallium-201 myocardial perfusion imaging over clinical and exercise stress test in low to intermediate risk patients: study in 1137 patients with 6-year follow- up. Circulation 1999; 100:1521-1527.

115. Olmos LI, Dakik H, Gordon R, et al. Long-term prognostic value of exercise echocardiography compared with exercise ${ }^{201} \mathrm{Tl}, \mathrm{ECG}$, and clinical variables in patients evaluated for coronary artery disease. Circulation 1998; 98:2679-2686.

116. Alkeylani A, Miller DD, Shaw LJ, et al. Influence of race on the prediction of cardiac events with stress technetium-99m sestamibi tomographic imaging in patients with stable angina pectoris. Am J Cardiol 1998; 81:293-297.

117. Snader CE, Marwick TH, Pashkow FJ, Harvey SA, Thomas JD, Lauer MS. Importance of estimated functional capacity as a predictor of all-cause mortality among patients referred for exercise thallium single-photon emission computed tomography: report of 3,400 patients from a single center. $J$ Am Coll Cardiol 1997; 30:641-648.

118. Boyne TS, Koplan BA, Parsons WJ, Smith WH, Watson DD, Beller GA. Predicting adverse outcome with exercise SPECT technetium-99m sestamibi imaging in patients with suspected or known coronary artery disease. Am J Cardiol 1997; 79: 270-274.

119. Geleijnse ML, Elhendy A, van Domburg RT, et al. Cardiac imaging for risk stratification with dobutamine-atropine stress testing in patients with chest pain. Echocardiography, perfusion scintigraphy, or both? Circulation 1997; 96:137147.

120. Heller GV, Herman SD, Travin MI, Baron JI, Santos-Ocampo C, McClellan JR. Independent prognostic value of intrave- 
nous dipyridamole with technetium-99m sestamibi tomographic imaging in predicting cardiac events and cardiacrelated hospital admissions. J Am Coll Cardiol 1995; 26:1202-1208.

121. Machecourt J, Longere P, Fagret D, et al. Prognostic value of thallium-201 single-photon emission computed tomographic myocardial perfusion imaging according to extent of myocardial defect. Study in 1,926 patients with follow-up at 33 months. J Am Coll Cardiol 1994; 23:1096-1106.

122. Kamal AM, Fattah AA, Pancholy S, et al. Prognostic value of adenosine single-photon emission computed tomographic thallium imaging in medically treated patients with angiographic evidence of coronary artery disease. J Nucl Cardiol 1994; 1:254-261.

123. Stratmann HG, Tamesis BR, Younis LT, Wittry MD, Miller DD. Prognostic value of dipyridamole technetium-99m sestamibi myocardial tomography in patients with stable chest pain who are unable to exercise. Am J Cardiol 1994; 73:647-652.

124. Stratmann HG, Williams GA, Wittry MD, Chaitman BR, Miller DD. Exercise technetium-99m sestamibi tomography for cardiac risk stratification of patients with stable chest pain. Circulation 1994; 89:615-622.

125. Groutars RG, Verzijlbergen JF, Muller AJ, et al. Prognostic value and quality of life in patients with normal rest thallium201/stress technetium 99m-tetrofosmin dual-isotope myocardial SPECT. J Nucl Cardiol 2000; 7:333-341.

126. Gibbons RJ, Hodge DO, Berman DS, et al. Long-term outcome of patients with intermediate-risk exercise electrocardiograms who do not have myocardial perfusion defects on radionuclide imaging. Circulation 1999; 100:2140-2145.

127. Soman P, Parsons A, Lahiri N, Lahiri A. The prognostic value of a normal Tc-99m sestamibi SPECT study in suspected coronary artery disease. J Nucl Cardiol 1999; 6:252-256.

128. Mark DB, Shaw L, Harrell FE, et al. Prognostic value of a treadmill exercise score in outpatients with suspected coronary artery disease. $N$ Engl J Med 1991; 325:849-853.

129. Deleted in proofs.

130. Wagdy HM, Hodge D, Christian TF, Miller TD, Gibbons RJ. Prognostic value of vasodilator myocardial perfusion imaging in patients with left bundle-branch block. Circulation 1998; 97:1563-1570.

131. Navare SM, Mather JF, Fowler MS, Shaw LJ, Heller GV. Are there differences in risk stratification of patients with known or suspected coronary disease between pharmacologic and exercise stress myocardial perfusion imaging? A meta-analysis [abstract]. J Nucl Cardiol 2002; 4:S22.

132. Bateman TM, O'Keefe JH Jr, Dong VM, Barnhart C, Ligon RW. Coronary angiography rates following stress SPECT scintigraphy. J Nucl Cardiol 1995; 2:217-223.

133. O Keefe JH, Bateman TM, Ligon RW, et al. Outcome of medical versus invasive treatment for non high risk ischaemic heart disease. J Nucl Cardiol 1998; 5:28-33.

134. Gibbons RJ, Antman EM, Alpert JS, et al. ACC/AHA guideline update for perioperative cardiovascular evaluation for noncardiac surgery. J Am Coll Cardiol 2002; 39:542-553.

135. Boucher CA, Brewster DC, Darling C, Okada R, Strauss HW. Determination of cardiac risk by dipyridamole-thallium imaging before peripheral vascular surgery. $N$ Engl J Med 1985; 312:389-394.

136. Cutler BS, Leppo JA. Dipyridamole thallium 201 scintigraphy to detect coronary artery disease before abdominal aortic surgery. J Vasc Surg 1987; 5:91-100.
137. Fletcher JP, Antico VF, Gruenewald S, Kershaw LZ. Dipyridamole-thallium scan for screening of coronary artery disease prior to vascular surgery. J Cardiovasc Surg (Torino) 1988; 29:666-669.

138. Sachs RN, Tellier P, Larmignat P, et al. Assessment by dipyridamole-thallium-201 myocardial scintigraphy of coronary risk before peripheral vascular surgery. Surgery 1988; 103: 584-587.

139. Eagle KA, Coley CM, Newell JB, et al. Combining clinical and thallium data optimizes preoperative assessment of cardiac risk before major vascular surgery. Ann Intern Med 1989; 110:859-866.

140. McEnroe CS, O’Donnell RF, Jr., Yeager A, Konstam M, Mackey WC. Comparison of ejection fraction and Goldman risk factor analysis of dipyridamole-thallium-201 studies in the evaluation of cardiac morbidity after aortic aneurysm surgery. J Vasc Surg 1990; 11:497-504.

141. Younis LT, Aguirre F, Byers S, et al. Perioperative and longterm prognostic value of intravenous dipyridamole thallium scintigraphy in patients with peripheral vascular disease. Am Heart J 1990; 119:1287-1292.

142. Mangano DT, London MJ, Tubau JF, et al. Dipyridamole thallium-201 scintigraphy as a preoperative screening test. A reexamination of its predictive potential. Study of Perioperative Ischemia Research Group. Circulation 1991; 84:493502.

143. Strawn DJ, Guernsey JM. Dipyridamole thallium scanning in the evaluation of coronary artery disease in elective abdominal aortic surgery. Arch Surg 1991; 126:880-884.

144. Watters TA, Botvinick EH, Dae MW, et al. Comparison of the findings on preoperative dipyridamole perfusion scintigraphy and intraoperative transesophageal echocardiography: implications regarding the identification of myocardium at ischemic risk. J Am Coll Cardiol 1991; 18:93-100.

145. Hendel RC, Whitfield SS, Villegas BJ, Cutler BS, Leppo JA. Prediction of late cardiac events by dipyridamole thallium imaging in patients undergoing elective vascular surgery. $A m$ J Cardiol 1992; 70:1243-1249.

146. Lette J, Waters D, Cerino M, Picard M, Champagne P, Lapointe J. Preoperative coronary artery disease risk stratification based on dipyridamole imaging and a simple threestep, three-segment model for patients undergoing noncardiac vascular surgery or major general surgery. Am J Cardiol 1992; 69:1553-1558.

147. Madsen PV, Vissing M, Munck O, Kelbaek H. A comparison of dipyridamole thallium 201 scintigraphy and clinical examination in the determination of cardiac risk before arterial reconstruction. Angiology 1992; 43:306-311.

148. Brown KA, Rowen M. Extent of jeopardized viable myocardium determined by myocardial perfusion imaging best predicts perioperative cardiac events in patients undergoing noncardiac surgery. J Am Coll Cardiol 1993; 21:325-330.

149. Kresowik TF, Bower TR, Garner SA, et al. Dipyridamole thallium imaging in patients being considered for vascular procedures. Arch Surg 1993; 128:299-302.

150. Baron JF, Mundler O, Bertrand M, et al. Dipyridamole-thallium scintigraphy and gated radionuclide angiography to assess cardiac risk before abdominal aortic surgery. $N$ Engl $J$ Med 1994; 330:663-669.

151. Bry JD, Belkin M, O’Donnell TF Jr, et al. An assessment of the positive predictive value and cost-effectiveness of dipyridamole myocardial scintigraphy in patients undergoing vascular surgery. J Vasc Surg 1994; 19:112-121. 
152. Koutelou MG, Asimacopoulos PJ, Mahmarian JJ, Kimball KT, Verani MS. Preoperative risk stratification by adenosine thallium 201 single- photon emission computed tomography in patients undergoing vascular surgery. J Nucl Cardiol 1995; 2:389-394.

153. Marshall ES, Raichlen JS, Forman S, Heyrich GP, Keen WD, Weitz HH. Adenosine radionuclide perfusion imaging in the preoperative evaluation of patients undergoing peripheral vascular surgery. Am J Cardiol 1995; 76:817-821.

154. Van Damme H, Pierard L, Gillain D, Benoit T, Rigo P, Limet R. Cardiac risk assessment before vascular surgery: a prospective study comparing clinical evaluation, dobutamine stress echocardiography, and dobutamine Tc-99m sestamibi tomoscintigraphy. Cardiovasc Surg 1997; 5:54-64.

155. Camp AD, Garvin PJ, Hoff J, Marsh J, Byers S, Chaitman BR. Prognostic value of intravenous dipyridamole thallium imaging in patients with diabetes mellitus considered for renal transplantation. Am J Cardiol 1990; 65:1459-1463.

156. Iqbal A, Gibbons RJ, McGoon MD, Steiroff S, Frohnert P, Velosa JA. Noninvasive assessment of cardiac risk in insulindependent diabetic patient being evaluated for pancreatic transplantation using thallium-201 myocardial perfusion scintigraphy. Transpl Proc 1991; 23:1690-1691.

157. Coley CM, Field TS, Abraham SA, Boucher CA, Eagle KA. Usefulness of dipyridamole-thallium scanning for preoperative evaluation of cardiac risk for nonvascular surgery. Am J Cardiol 1992; 69:1280-1285.

158. Shaw L, Miller DD, Kong BA, et al. Determination of perioperative cardiac risk by adenosine thallium-201 myocardial imaging. Am Heart J 1992; 124:861-869.

159. Takase B, Younis LT, Byers SL, et al. Comparative prognostic value of clinical risk indexes, resting two-dimensional echocardiography, and dipyridamole stress thallium-201 myocardial imaging for perioperative cardiac events in major nonvascular surgery patients. Am Heart J 1993; 126:10991106.

160. Younis L, Stratmann H, Takase B, Byers S, Chaitman BR, Miller DD. Preoperative clinical assessment and dipyridamole thallium-201 scintigraphy for prediction and prevention of cardiac events in patients having major noncardiovascular surgery and known or suspected coronary artery disease. Am J Cardiol 1994; 74:311-317.

161. Stratmann HG, Younis LT, Wittry MD, Amato M, Miller DD. Dipyridamole technetium-99m sestamibi myocardial tomography in patients evaluated for elective vascular surgery: prognostic value for perioperative and late cardiac events. Am Heart J 1996; 131:923-929.

162. Klein W. Cardiovascular disease at the turn of the millennium: focus on Europe. Eur Heart J 2001; 3 (Suppl):M2-M6.

163. Stangl V, Beaumann G, Stangl K. Coronary atherogenic risk factors in women. Eur Heart J 2002; 23:1738-1752.

164. Mautner SL, Lin F, Mautner GC, Roberts WC. Comparison in women versus men of composition of atherosclerotic plaques in native coronary arteries and saphenous veins used as aorto-coronary conduits. J Am Coll Cardiol 1993; 21: 1312-1318.

165. Devries S, Wolfkiel C, Fusman B, et al. Influence of age and gender on the presence of coronary calcium detected by ultrafast computed tomography. J Am Coll Cardiol 1995; 25 : $76-82$.

166. Kwok Y, Kim C, Grady D, Segal M, Redberg R. Meta-analysis of exercise testing to detect coronary artery disease in women. Am J Cardiol 1999; 83:660-666.
167. Cerqueira MD. Diagnostic testing strategies for coronary artery disease: specific issues related to gender. Am J Cardiol 1995; 75:52-60D.

168. Hachamovitch R, Berman DS, Kiat H, et al. Effective risk stratification using exercise myocardial perfusion SPECT in women: gender-related differences in prognostic nuclear testing. J Am Coll Cardiol 1996; 28:34-44.

169. Marwick TH, Shaw LJ, Laurere MS, et al. The noninvasive prediction of cardiac mortality in man and women with known or suspected coronary artery disease. Am J Med 1999; 106:172-178.

170. Shaw LJ, Hachamovitch R, Redberg RF. Current evidence on diagnostic testing in women with suspected coronary artery disease: choosing the appropriate test. Cardiol Rev 2000; 8:65-74.

171. Pancholy SB, Fattah AA, Kamal AM, et al. Independent and incremental prognostic value of exercise thallium singlephoton emission computed tomographic imaging in women. J Nucl Cardiol 1995; 2:110-116.

172. Amanullah AM, Berman DS, Erel J, et al. Incremental prognostic value of adenosine myocardial perfusion SPECT in women with suspected coronary artery disease. Am J Cardiol 1998; 82:725-730.

173. McIntyre K, Stewart S, Capewell S, et al. Gender and survival: a population based study of 201,114 men and women following first myocardial infarction. J Am Coll Cardiol 2001; 38:729-735.

174. Mobasseri S, Hendel RC. Cardiac imaging in women: use of radionuclide myocardial perfusion imaging and echocardiography for acute chest pain. Cardiol Rev 2002; 10:149-160.

175. Kwok JM, Miller TD, Hodge DO, Gibbons RJ. Prognostic value of the Duke treadmill score in the elderly. J Am Coll Cardiol 2002; 39:1475-1481.

176. Shaw LJ, Miller D. Noninvasive coronary risk stratification of elderly patients. Am J Geriatr Cardiol 1994; 3:12-21.

177. Steingert RM, Hodnett P, Musso J, Feuerman M. Exercise myocardial perfusion imaging in elderly patients. $J$ Nucl Cardiol 2002; 9:573-580.

178. Kurata C, Uehara A, Sugi T, et al. Exercise myocardial perfusion scintigraphy is useful for evaluating myocardial ischaemia even in the elderly. Ann Nucl Med 2000; 14:181186.

179. Hachomovitch R, Berman DS, Kiat H, et al. Exercise myocardial perfusion SPECT in patients without known coronary artery disease. Incremental prognostic value and use in risk stratification. Circulation 1996; 93:905-914.

180. Timmis AD. Diabetic heart disease: clinical considerations. Heart 2001:85:463-469.

181. Giri S, Shaw LJ, Murthy DR, et al. Impact of diabetes on risk stratification using stress single photon emission computed tomography myocardial perfusion imaging in patients with symptoms suggestive of coronary artery disease. Circulation 2002; 105:32-40.

182. Schinkel AF, Elhendy A, van Domburg RT, et al. Prognostic value of dobutamine-atropine stress myocardial perfusion imaging in patients with diabetes. Diabetes Care 2002; 25: 1637-1643.

183. Inoguchi T, Yamashita T, Umeda F, et al. High incidence of silent myocardial ischaemia in elderly patients with non insulindependent diabetes mellitus. Diabetes Res Clin Pract 2000; 47:37-44.

184. Kang X, Berman DS, Lewin HC, et al. Incremental prognostic value of myocardial perfusion single photon emission 
computed tomography in patients with diabetes mellitus. Am Heart J 1999; 138:1025-1032.

185. Faglia E, Favales F, Calia P, et al. Cardiac events in 735 type 2 diabetic patients who underwent screening for unknown asymptomatic coronary heart disease 5 year follow-up report from the Milan study on Atherosclerosis and Diabetes (MiSAD). Diabetes Care 2002; 25:2032-2036.

186. Wackers FJT, Zaret BL. Detection of myocardial ischemia in patients with diabetes mellitus. Circulation 2002; 105:5-7.

187. Bhopal R, Sengupta-Wiebe S. Cardiovascular risks and outcomes: ethnic variations in hypertensive patients. Heart 2000; 83:495-496.

188. Khattar RS, Swales JD, Senior R, Lahiri A. Racial variations in cardiovascular morbidity and mortality in essential hypertension. Heart 2000; 83:267-271.

189. Okelo S, Taylor AL, Wright J, et al. Race and the decision to refer for coronary revascularization. J Am Coll Cardiol 2001; 38:698-704.

190. Bateman TM, O'Keefe JH Jr, Williams ME. Incremental value of myocardial perfusion scintigraphy in prognosis and outcomes of patients with coronary artery disease. Curr Opin Cardiol 1996; 11:613-620.

191. Diaz La, Brunken RC, Blackstone EH, Snader CE, Lauer MS. Independent contribution of myocardial perfusion defects to exercise capacity and heart rate recovery for prediction of allcause mortality in patients with known or suspected coronary heart disease. J Am Coll Cardiol 2001; 37:1558-1564.

192. Berman DS, Kang X, Schisterman EF, et al. Serial changes on quantitative myocardial perfusion SPECT in patients undergoing revascularization or conservative therapy. $\mathrm{J} \mathrm{Nucl}$ Cardiol 2001; 8:428-437.

193. Helber U, Muller-Schauenburg W, Hoffmeister HM. Quantification of viable myocardium in multivessel coronary disease: effects of the redistribution time after reinjection of thallium-201 and comparison with postrevascularization defect size. Int J Angiology 1999; 8:36-39.

194. Pace L, Perrone-Filardi P, Mainenti PP, et al. Effects of myocardial revascularization on regional thallium-201 uptake and systolic function in regions with reverse redistribution on tomographic thallium-201 imaging at rest in patients with chronic coronary artery disease. J Nucl Cardiol 1998; 5:153160 .

195. Kitsiou AN, Srinivasan G, Quyyumi AA, Summers RM, Bacarach SL, Dilsizian V. Stress-induced reversible and mild-to-moderate irreversible thallium defects: Are they equally accurate for predicting recovery of regional left ventricular function after revascularization? Circulation 1998; 98:501-508.

196. Leoncini M, Sciagra R, Maioli M, et al. Usefulness of dobutamine Tc-99m sestamibi-gated SPECT for prediction of LVEF outcome after coronary revascularization for ischemic cardiomyopathy. Am J Cardiol 2002; 89:817-821.

197. Desideri A, Candelpergher G, Zanco P, et al. Exercise technetium $99 \mathrm{~m}$ sestamibi single-photon emission computed tomography late after coronary artery bypass surgery: longterm follow-up. Clin Cardiol 1997; 20:779-784.

198. Morse RW, Noe S, Caravalho J Jr, Balingit A, Taylor AJ. Rest-redistribution ${ }^{201} \mathrm{Tl}$ SPECT imaging for determination of myocardial viability: relationship among viability, mode of therapy, and long-term prognosis. Chest 1999; 115:16211626.

199. Gonzalez JM, Castll-Conesa J, Candell-Riera J, RosselloUrgell J. Relevance of 99mTc-MIBI rest uptake, ejection frac- tion and location of contractile abnormality in predicting myocardial recovery after revascularization. Nucl Med Commun 2001; 22:795-805.

200. Perrone-Filardi P, Chiariello M, Underwood SR. The assessment of myocardial viability and hibernation using resting thallium imaging. Clin Cardiol 2000; 23:719-722.

201. Oudiz RJ, Smith DE, Pollak AJ, et al. Nitrate-enhanced ${ }^{201} \mathrm{Tl}$ SPECT imaging in hibernating myocardium. Am Heart $J$ 1999; 138:369-375.

202. Gunning MG, Anagnostopoulos C, Davies G, et al. Simultaneous assessment of myocardial viability and function for the detection of hibernating myocardium using ECG-gated ${ }^{99} \mathrm{Tc}(\mathrm{m})$-tetrofosmin emission tomography: a comparison with ${ }^{201} \mathrm{Tl}$ emission tomography combined with cine MR imaging. Nucl Med Commun 1999; 20:209-214.

203. Pace L, Perrone-Filardi P, Mainenti P, et al. Identification of viable myocardium in patients with chronic coronary artery disease using rest-redistribution ${ }^{201} \mathrm{Tl}$ tomography: optimal image analysis. J Nucl Med 1998; 39:1869-1874.

204. Schafers M, Matheja P, Hasfeld M, et al. The clinical impact of ${ }^{201} \mathrm{Tl}$ reinjection for the detection of myocardial hibernation. Eur J Nucl Med 1996; 23:407-413.

205. Hardoff R, Shafer A, Gips S, et al. Predicting late restenosis after coronary angioplasty by very early (12 to $24 \mathrm{~h}$ ) thallium201 scintigraphy: implications with regards to mechanism of late restenosis. J Am Coll Cardiol 1990; 15:1486-1492.

206. Elhendy A, van Domburg RT, Bax JJ, et al. Dobutamine-atropine stress myocardial perfusion SPECT imaging in the diagnosis of graft stenosis after coronary artery bypass grafting. J Nucl Cardiol 1998; 5:533-537.

207. Lakkis NM, Mahmarian JJ, Verani MS. Exercise thallium201 single photon emission computed tomography for evaluation of coronary artery bypass graft patency. Am J Cardiol 1996; 78:608.

208. Shapira I, Heller I, Kornizky Y, Topilsky M, Isakov A. The value of stress thallium-201 single photon emission CT imaging as a predictor of outcome and long-term prognosis after CABG. J Nucl Med 2001; 32:271-282.

209. Lauer MS, Lytle B, Pashkow F, et al. Prediction of death and myocardial infarction by screening with exercise thallium testing after coronary artery bypass grafting. Lancet 1998; 351:615-622.

210. Nallamothu N, Johnson JH, Bagheri B, et al. Utility of stress single photon emission computed tomography (SPECT) perfusion imaging in predicting outcome after coronary artery bypass grafting. Am J Cardiol 1997; 80:1515-1521.

211. Sarda L, Fuchs L, Lebtahi R, et al. Prognostic value of ${ }^{201} \mathrm{~T} 1$ myocardial scintigraphy after coronary artery bypass grafting. Nucl Med Commun 2001; 22:189-196.

212. Kaminek M, Myslivecek M, Skvarilova M, Husak V, Koranda P, Lang O. Prognostic value of myocardial perfusion tomographic imaging in patients after percutaneous transluminal coronary angioplasty. Clin Nucl Med 2000; 25:775778.

213. Alazraki NP, Krawczynska EG, Kosinski AS, et al. Prognostic value of thallium-201 single-photon emission computed tomography for patients with multivessel coronary artery disease after revascularisation (the Emory Angioplasty versus Surgery Trial [EAST]). Am J Cardiol 1999; 84:1369-1374.

214. Palmas W, Bingham S, Diamond GA, et al. Incremental prognostic value of exercise thallium-201 myocardial single photon emission tomography late after coronary artery bypass surgery. J Am Coll Cardiol 1995; 26:1560-1562. 
215. Nallamothu N, Johnson JH, Bagheri B, Heo J, Iskandrian AE. Utility of stress single-photon emission computed tomography (SPECT) perfusion imaging in predicting outcome after coronary artery bypass grafting. Am J Cardiol 1997; 80:1517-1521.

216. Zellweger MJ, Lewin HC, Lai S, et al. When to stress patients after coronary artery bypass surgery? Risk stratification in patients early and late post-CABG using stress myocardial perfusion SPECT: implications of appropriate clinical strategies. J Am Coll Cardiol 2001; 37:144-152.

217. Schinkel AFL, Elhendy A, van Domburg RT, et al. Longterm prognostic value of dobutamine stress $99 \mathrm{mTc}$-sestamibi SPECT: single-centre experience with 8-year follow-up. Radiology 2002; 225:701-706.

218. Manyari DE, Knudtson M, Kloiber R, Roth D. Sequential thallium-201 myocardial perfusion studies after successful percutaneous transluminal coronary artery angioplasty: delayed resolution of exercise-induced scintigraphic abnormalities. Circulation 1988; 77:86-95.

219. Hecht HS, Shaw RE, Chin HL, Ryan C, Stertzer SH, Myler RK. Silent ischaemia after coronary angioplasty: evaluation of restenosis and extent of ischaemia in asymptomatic patients by tomographic thallium-201 exercise imaging and comparison with symptomatic patients. J Am Coll Cardiol 1991; 17:670-677.

220. Department of Health. National Service Framework for Coronary Heart Disease. Leeds: Department of Health 2000. Available from http.//ww.doh.gov.uk/nsf/coronary.htm.

221. British Cardiac Society Guidelines and Medical Practice Committee and Royal College of Physicians Clinical Effectiveness and Evaluation Unit. Guidelines for the management of patients with acute coronary syndromes without persistent ECG ST segment elevation. Heart 2001; 85:133-142.

222. Farkouh ME, Smars P, Reeder G.S, et al. A clinical trial of a chest pain observation unit for patients with unstable angina. N Eng J Med 1998; 339:1882-1888.

223. Goodacre SW. Should we establish chest pain observation units in the UK? A systematic review and critical appraisal of the literature. J Accid Emerg Med 2000; 17:1-6(S).

224. Stratmann HG, Younis LT, Wittry MD, et al. Exercise technetium-99m myocardial tomography for the risk stratification of men with medically treated unstable angina pectoris. Am J Cardiol 1995; 76:235-240.

225. Stratman HG, Tamesis BR, Younis LT, et al. Prognostic value of predischarge dipyridamole technetium sestamini myocardial tomography in medically treated patient with unstable angina. Am Heart J 1995; 130:734-740.

226. Bilodeau L, Theroux P, Gregoire J, et al. Technetium-99m sestamibi tomography in patients with spontaneous chest pain: correlations with clinical electrocardiographic and angiographic findings. J Am Coll Cardiol 1991; 18:1684-1691.

227. Christian TF, Clements IP, Gibbons RJ, et al. Non-invasive identification of myocardium at risk in patients with acute myocardial infarction and non diagnostic electrocardiograms with technetium-99m sestamibi. Circulation 1991; 83:1615-1620.

228. Hilton TC, Thompson RC, Williams H, et al. Technetium99m sestamibi myocardial perfusion imaging in the emergency room evaluation of chest pain. J Am Coll Cardiol 1994; 23:1016-1022.

229. Varetio T, Cantalupi D, Altieri A, et al. Emergency room technetium-99m sestamibi imaging to rule out acute myocardial ischaemic events in patients with non diagnostic elctrocardiography. J Am Coll Cardiol 1993; 22:1804-1808.
230. Tatum JL, Jesse RI, Kontos MC, et al. Comprehensive strategy for the evaluation and triage of the chest pain patient. Ann Emerg Med 1997; 29:116-125.

231. Ziffer JA, Nateman DR, Janowitz WR, et al. Improved patient outcomes: cost effectiveness of utilizing nuclear cardiology protocols in an emergency department chest pain centre [abstract]. J Nucl Med 1998:39:13p.

232. Heller GV, Stowers SA, Hendel RC, et al. Clinical value of acute rest technetium-99m tetrofosmin tomographic myocardial perfusion imaging in patients with acute chest pain and non diagnostic electrocardiogram. J Am Coll Cardiol 1998; 31:1011-1017.

233. Kontos MC, Jesse RL, Anderson FP, et al. Comparison of myocardial perfusion imaging and cardiac troponin I in patients admitted to the emergency department with chest pain. Circulation 1999; 99:2073-2078.

234. Stowers SA, Eisenstein EL, Wackers T, et al. An economic analysis of an aggressive diagnostic strategy with single photon emission computed tomography myocardial perfusion imaging and early exercise stress testing in emergency department patients who present with chest pain but nondiagnostic electrocardiograms: results from a randomized trial. Ann Emerg Med 2000; 35:17-25.

235. Udelson JE. The Emergency Room Assessment of Sestamibi for the Evaluation of Chest Pain Trial. Proceedings of the 72nd meeting of the American Heart Association. Atlanta, USA, November 1999.

236. Joint Royal College of Physicians/British Cardiac Society Fifth Joint Report on the Provision of Cardiac Services. Heart 2002; 88:supplement in press.

237. Braunwald EB, et al. Unstable angina clinical practice guideline number 10. Agency for Health Care Policy and Research publication No. 94-0602, 1994.

238. Brown KA. Management of unstable angina: the role on noninvasive risk stratification. J Nucl Cardiol 1997; 4:S164S168.

239. Fox KAA, Poole-Wilson PA, Henderson RA, et al. Interventional versus conservative treatment for patients with unstable angina or non ST elevation myocardial infarction: The British Heart Foundation RITA 3 Randomised Trial. Lancet 2002; 360:743-751.

240. Mehta S, Yousuf S, Hunt D, et al. Invasive versus conservative management of unstable angina and non Q-wave myocardial infarction: a meta-analysis. Circulation 1999; 100:I775 .

241. Solomon DH, Stone PH, Glynn RJ, et al. Use of risk stratification to identify patients with unstable angina likeliest to benefit from an invasive versus conservative management strategy. J Am Coll Cardiol 2001; 38:969-976.

242. Cannon CP, Weintaub WS, Demopoulos LA, et al. Comparison of early invasive and conservative strategies in patients with unstable coronary syndromes treated with the glycoprotein IIb/IIIa inhibitor tirofiban. $N$ Engl J Med 2001; 344: 1879-1887.

243. van der Werf F, Ardissino D, Betriu A, et al. Management of acute myocardial infarction in patients presenting with STsegment elevation. Eur Heart J 2003; 24:28-66.

244. Ryan TJ, Antman EM, Brookes NH, et al. ACC/AHA Guidelines for the management of patients with acute myocardial infarction: executive summary and recommendations. Circulation 1999; 100:1016-1029.

245. Brown KA, Heller GV, Landin RS, et al. Early dipyridamole Tc-99m sestamibi single photon emission computed tomo- 
graphic imaging 2 to 4 days after acute myocardial infarction predicts in-hospital and post-discharge cardiac events: comparison with submaximal exercise imaging. Circulation 1999; 100:2060-2066.

246. Mahmarian JJ, Mahmarian AC, Marks GF, Pratt CM, Verani MS. Role of adenosine thallium-201 tomography for defining long-term risk in patients after acute myocardial infarction. J Am Coll Cardiol 1995; 25:1333-1340.

247. Dakik HA, Mahmarian JJ, Kimball KT, et al. Prognostic value of exercise ${ }^{201} \mathrm{Tl}$ tomography in patients treated with thrombolytic therapy during acute myocardial infarction. Circulation 1996; 94:2735-2742.

248. Travin MI, Dessouki A, Cameron T, Heller GV. Use of exercise technetium-99m sestamibi SPECT imaging to detect residual ischaemia and for risk stratification after acute myocardial infarction. Am J Cardiol 1995; 75:665-669.

249. Basu S, Senior R, Raval U, Lahiri A. Superiority of nitrateenhanced ${ }^{201} \mathrm{TI}$ over conventional redistribution ${ }^{201} \mathrm{TI}$ imaging for prognostic evaluation after myocardial infarction and thrombolysis. Circulation 1997; 96:2932-2937.

250. Ellis SG, Mooney MR, George BS, et al. Randomised trial of late elective angioplasty versus conservative management for patients with residual stenosos after thrombolytic treatment for myocardial infarction (TOPS Trial). Circulation 1992; 86:1400-1406.

251. Shaw LJ, Eisenstein EL, Hachamovitch R, Kesler KL, Heller GV, Miller DD. A primer of biostatistic and economic methods for diagnostic and prognostic modeling in nuclear cardiology: Part II. J Nucl Cardiol 1997; 4:52-60.

252. Underwood SR, Godman B, Salyani S, Ogle JR, Ell PJ. Economics of myocardial perfusion imaging in Europe-The EMPIRE study. Eur Heart J 1999; 20:157-166.

253. Mark DB, Shaw LJ, Lauer MS, O'Malley PG, Heidenreich P. 34th Bethesda Conference: Task force \#5-Is atherosclerosis imaging cost effective? J Am Coll Cardiol 2003; 41:19061917.

254. Maddahi J, Ghambir SS. Cost-effective selection of patients for coronary angiography. J Nucl Cardiol 1997; 4:S141S151.

255. Shaw LJ, Hachamovitch R, Eisenstein E, et al. Cost implications for implementing a selective preoperative risk screening approach for peripheral vascular surgery patients. Am J Managed Care 1997; 3:1817-1827.

256. Garber AM, Solomon NA. Cost-effectiveness of alternative test strategies for the diagnosis of coronary artery disease. Ann Intern Med 1999; 130:719-728.

257. Goldman L, Garber AM, Grover SA, Hlatky MA. 27th Bethesda Conference: matching the intensity of risk factor management with the hazard for CAD events. Task Force 6: Cost effectiveness of assessment and management of risk factors. J Am Coll Cardiol 1996; 27:1020-1030.

258. Patterson RE, Eng C, Horowitz SF, Gorlin R, Goldstein SR. Bayesian comparison of cost-effectiveness of different clinical approaches to coronary artery disease. J Am Coll Cardiol 1984; 4:278-289.

259. Kuntz KM. Cost-effectiveness of diagnostic strategies for patients with chest pain. Ann Intern Med 1999; 130:709718.

260. Wong JB, Sonnenberg FA, Salem DN, Pauker SG. Myocardial revascularization for chronic stable angina. Analysis of the role of percutaneous transluminal coronary angioplasty based on data available in 1989. Ann Intern Med 1990; 113:852-871.
261. Goldman L, Weinstein MC, Goldman PA, Williams LW. Cost-effectiveness of HMG-CoA reductase inhibition for primary and secondary prevention of coronary heart disease. JAMA 1991; 265:1145-1151.

262. Shaw LJ, Hachamovitch R, Berman DS, et al. The economic consequences of available diagnostic and prognostic strategies for the evaluation of stable angina patients: an observational assessment of the value of precatheterization ischemia. Economics of Noninvasive Diagnosis (END) Multicenter Study Group. J Am Coll Cardiol 1999; 33:661-669.

263. Shaw LJ, Marwick TH, Sawada S, et al. Prognostic value of exercise echocardiography versus SPECT imaging in 9521 intermediate pretest risk patients [abstract]. Circulation 2002; 106 (Suppl II):II-610.

264. Lee DS, Jang MJ, Cheon GJ, Chung JK, Lee MC. Comparison of the cost-effectiveness of stress myocardial perfusion SPECT and stress echocardiography in suspected coronary artery disease considering the prognostic value of false-negative results. J Nucl Cardiol 2002; 9:515-522.

265. Bateman TM. Nuclear cardiology in private practice. $J$ Nucl Cardiol 1997; 4:S184-S188.

266. Wong Y, Rodwell A, Dawkins S, Livesey SA, Simpson IA. Sex differences in investigation results and treatment in subjects referred for investigation of chest pain. Heart 2001; 85:149-152.

267. Underwood SR. Cost-effective investigation of chest pain (electronic correspondence). Heart $2001 \mathrm{http} / / /$ heart.bmjjournals. com/cgi/eletters/85/2/149.

268. Scanlon PJ, Faxon DP, Audet AM, et al. ACC/AHA guidelines for coronary angiography. J Am Coll Cardiol 1999; $33: 1756-1824$.

269. Shaw LJ, Hachamovitch R, Papatheofanis FJ. Outcomes and technology assessment in nuclear medicine. Reston, VA: Society of Nuclear Medicine Press, 1999.

270. Gibbons RJ, Balady GJ, Brocker JT, et al. ACC/AHA 2002 guideline update for exercise testing: a report of the American College of Cardiology/American Heart Association Task Force on Practice Guidelines (Committee on Exercise Testing) 2002. Available at www.acc.org/clinical/guidelines/exercise/ dirIndex.htm.

271. Klocke FJ, Baird MG, Bateman TM, et al. ACC/AHA/ASNC guidelines for clinical use of cardiac radionuclide imaging. J Am Coll Cardiol 2003; 42:1318-1333.

272. Gibbons RJ, Abrams J, Chatterjee K, et al. ACC/AHA 2002 guideline update for the management of patients with chronic stable angina. J Am Coll Cardiol 2003; 41:159-168.

273. Mieres JH, Shaw LJ, Hendel RC, et al. Consensus statement. American Society of Nuclear Cardiology: Task Force on Women and Coronary Artery Disease. The role of myocardial perfusion imaging in the clinical evaluation of coronary artery disease in women. Available at http://www.asnc.org/.

274. De Puey G, Garcia EV. Updated imaging guidelines for nuclear cardiology procedures: Part 1. J Nucl Cardiol 2001:8: G1-G58.

275. Bertrand ME, Simoons ML, Fox KAA, et al. Management of acute coronary syndromes in patients presenting without persistent ST-segment elevation. The Task Force on the Management of Acute Coronary Syndromes of the European Society of Cardiology. Eur Heart J 2002; 23:1809-1840.

276. de Bono D, for the joint working party of the British Cardiac Society and Royal College of Physicians of London. Investigation and management of stable angina: revised guidelines 1998. Heart 1999; 81:546-555. 
277. Anagnostopoulos C, Harbinson M, Kelion A, et al. BNMS procedure guidelines for myocardial perfusion imaging (draft). Heart 2003; 89:1156 (also available at www.bncs.org.uk.

278. Guideline for the management of patients with acute coronary syndromes without persistent ECG ST segment elevation. British Cardiac Society Guideline and Medical Practice Committee, and Royal College of Physicians Clinical Effectiveness and Evaluation Unit. Heart 2001; 85:133142.

279. Underwood R, Gibson C, Tweddel A, Flint J. A survey of nuclear cardiological practice in Great Britain. The British Nuclear Cardiology Group. Br Heart J 1992; 67:273-277.

280. Pennell DJ, Prvulovich E, Tweddel A, Caplin J. Nuclear Cardiology in the UK: British Nuclear Cardiology Society Survey 1994. Nucl Med Commun 1998; 19:305-313.

281. Prvulovich E, Metcalfe MJ. Nuclear cardiology in the UK: activity and practice 1997. Eur J Nucl Med Mol Imaging 2002; 29:553-558.

282. Prvulovich EM, Jarritt PH, Vivian GC, Clarke SE, Pennell DJ, Underwood SR. Quality assurance in myocardial perfusion tomography: a collaborative BNCS/BNMS audit programme. Nucl Med Commun 1998; 19:831-838.

283. Jarritt PH, Prvulovich EM, Underwood SR, Yang GZ. Myocardial perfusion scintigraphy: an interactive CDROM train- ing programme of reporting skills. British Nuclear Cardiology Society and British Nuclear Medicine Society, 2000; London, UK. Available from http://www.bnms.org.

284. British Cardiac Society. Council statement on the demand and need for cardiac services and the development of a waiting list strategy for cardiac disease. British Cardiac Society, July 1994. http://www.bcs.com/doclibrary/bcsmembers/pub2.html.

285. A report of a working group of the British Cardiac Society. Cardiology in the district general hospital. Br Heart J 1994; 72:303-308.

286. Martin RM, Hemingway H, Gunnell D, Karsch KR, Baumbach A, Frankel S. Population need for coronary revascularisation: are national targets for England credible? Heart 2002; 88:627-633.

287. British Cardiovascular Intervention Society. BCIS audit returns 2001. Available at http://www.bcis.org.uk/audit/index.html.

288. Arlington Medical Resources. The Imaging Marketing Guide. Arlington VA and Brussels: AMR Inc.

289. Forbes E, Clarke SEM, Buxton-Thomas M, Burwood R, Nunan T, Craig J. The development of regional nuclear medicine audit in South Thames. Nucl Med Commun 1997; 18:693-697.

290. Giering LP, Smith JE. Industrial perspective: from IND to NDA. J Nucl Cardiol 1995; 2:66-70. 